\title{
Youth Homelessness: The Impact of Supportive Relationships on Recovery
}

Sara Gasior, The University of Western Ontario

Supervisor: Cheryl Forchuk, The University of Western Ontario

A thesis submitted in partial fulfillment of the requirements for the Master of Science degree in Nursing

(C) Sara Gasior 2015

Follow this and additional works at: https://ir.lib.uwo.ca/etd

Part of the Pediatric Nursing Commons, Psychiatric and Mental Health Nursing Commons, and the Public Health and Community Nursing Commons

\section{Recommended Citation}

Gasior, Sara, "Youth Homelessness: The Impact of Supportive Relationships on Recovery" (2015). Electronic Thesis and Dissertation Repository. 3233.

https://ir.lib.uwo.ca/etd/3233

This Dissertation/Thesis is brought to you for free and open access by Scholarship@Western. It has been accepted for inclusion in Electronic Thesis and Dissertation Repository by an authorized administrator of Scholarship@Western. For more information, please contact wlswadmin@uwo.ca. 


\section{YOUTH HOMELESSNESS: THE IMPACT OF SUPPORTIVE RELATIONSHIPS ON RECOVERY}

(Thesis format: Monograph)

by

\section{Sara Gasior}

Graduate Program in Nursing

A thesis submitted in partial fulfillment of the requirements for the degree of Masters of Science in Nursing

The School of Graduate and Postdoctoral Studies

The University of Western Ontario

London, Ontario, Canada

(C) Sara A. Gasior 2015 


\begin{abstract}
AIM: To test a model based on Peplau's theory of Interpersonal Relations, which examines the influence of a network of service providers, perceptions of social supports and perceptions of family relations on a homeless youth's perceptions of recovery.
\end{abstract}

BACKGROUND: Homeless youth comprise an extremely disenfranchised group and have been recognized as one of the fastest growing sub-groups within the homeless population. Homeless youth face impaired access to health and social services. They are often left unsupported and lack social and familial support or relationships with service providers. Homeless youth left unsupported frequently sink into a cycle of homelessness that extends into adulthood.

METHODS: This study is a secondary analysis and used a subsample of the original Youth Matters study. A predictive, non-experimental design was used to test the relationship of a network of service providers, perceived social support and perceived family relations on perceptions of recovery in the homeless youth population. A sample of homeless youth $(\mathrm{n}=187)$ in Ontario, Canada were interviewed at six month intervals over a 2.5 year period. Hierarchical multiple regression analysis was used.

RESULTS: Network of service providers, perceived social supports and perceived family relations explained $21.8 \%$ of the variance in homeless youth perceptions of recovery. Perceived social support and family relations were significantly, positively correlated to perceptions of recovery. Network of service providers was not significantly correlated to perceptions of recovery.

CONCLUSIONS: The findings suggest that stronger social supports and family relations may contribute to increased perceptions of recovery among homeless youth.

IMPLICATIONS FOR FUTURE PRACTICE: Health and social service providers must understand the importance of implementing interventions that foster supportive relationships and networks of support in the homeless youth population.

KEYWORDS: homeless; youth; recovery; social support; family; service provider 


\section{Co-Authorship}

Sara Gasior completed the following work under the supervision of Cheryl Forchuk and Sandra Regan who will be co-authors on the final publication from Chapter Two. Both members contributed to the work through their advisement on the development of the study, review of the analysis, and overall content and clarity of the writing. 


\section{Acknowledgements}

I would like to thank Cheryl Forchuk who has supported me throughout this entire process. Cheryl's advisement and knowledge has empowered me to develop my research and writing skills. I would also like to thank Sandra Regan for her support and guidance which furthered my knowledge in research and data analysis. Both Cheryl and Sandra provided continuous encouragement during the development and writing of this paper. I would also like to thank my family whose constant support, patience and love have allowed me to complete my studies. Lastly, I would like to thank my peers and co-workers who inspired me through their experiences and continuously provided support throughout the program and writing of this paper. 
Table of Contents

Abstract ii

$\begin{array}{ll}\text { Co-authorship } & \text { iii }\end{array}$

Acknowledgements $\quad$ iv

Table of Contents $\quad$ v

List of Tables vii

List of Figures viii

Chapter One

Background and Significance $\quad 2$

$\begin{array}{ll}\text { Statement of the Problem } & 6\end{array}$

$\begin{array}{ll}\text { Statement of Study Purpose } & 9\end{array}$

$\begin{array}{ll}\text { References } & 10\end{array}$

Chapter Two

$\begin{array}{ll}\text { Background } & 17\end{array}$

$\begin{array}{ll}\text { Theoretical Framework } & 20\end{array}$

$\begin{array}{ll}\text { Review of the Literature } & 23\end{array}$

Hypotheses and Rationale $\quad 30$

Methods

Design 32

Sample $\quad 32$

Instrumentation $\quad 34$

Data Analysis $\quad 38$

Results

Participant Characteristics $\quad 38$

Descriptive Results $\quad 38$

Relationships of Demographic Variables to Major Study

Variables $\quad 40$

Correlations among Study Variables $\quad 40$

Multiple Regression Analysis $\quad 41$

$\begin{array}{ll}\text { Discussion } & 44\end{array}$

Limitations $\quad 50$

Conclusion $\quad 51$

References $\quad 52$

Chapter Three

Implications for Nursing Practice $\quad 63$

Implications for Policy $\quad 66$ 
Implications for Service Provider Education

Recommendations for Future Research

Summary and Conclusion

69

References

Curriculum Vitae 


\section{List of Tables}

Table

Description

Page

1

Description of demographic characteristics of homeless youth

39

2

Means, Standard Deviations, Reliability and Correlations among study variables

Hierarchical Regression results for all models

43 


\section{List of Figures}

Figure Description $\quad$ Page

$1 \quad$ Peplau's Framework: Major Concepts and Their Inter-

Relationships 


\section{Chapter One}

The pathways into and out of homelessness are complex. Individuals, classified as "homeless", may not share many commonalities with one another aside from the fact that they are extremely vulnerable, lack adequate income, housing, and supports to ensure secure housing (Gaetz, Donaldson, Richter, \& Gulliver, 2013). There have been many efforts made to obtain a clearer understanding of the nature and extent of homelessness in Canada (Frankish, Hwang, \& Quantz, 2009). Efforts have extended across physical, mental, psychological, and emotional domains of living to reduce the extent of suffering that the homeless population endures. Recently, the youth population, between the ages of 16 to 25 , have become an area of focus as Canadian youth are the most vulnerable, comprising the fastest growing segment of the homeless population (Kulik, Gaetz, Crowe, \& Ford-Jones, 2011).

The numerous disadvantages of youth homelessness, including poor health and quality of life (QoL), increased risk of mental health and substance use issues, and limited supports, suggests that understanding the health challenges of homeless youth requires research in educational, nutritional, psychological, and physical domains (Medlow, Klineberg, \& Steinbeck, 2014). The interactions between mental and physical health conditions suggest that it is essential to widen the knowledge base regarding this population. This knowledge is important in the structuring of health programs as well as the education of service providers who will be better able to look beyond the crisis conditions that bring homeless youth into their care and the disabling conditions that produce long-term mental and physical health problems (Evenson, 2009; Darbyshire, Muir-Cochrane, Fereday, Jureidini, \& Drummon, 2006; Dawson \& Jackson, 2013). 


\section{Background and Significance}

The first efforts to estimate the extent of homelessness across Canada began in 1987 through the work of the Canadian Council on Social Development (Begin et al., 1999). Since then, data from the 2001 Census by Statistics Canada (2002) indicated that over 14000 individuals were homeless on a national level. This number is believed to vastly under-represent the problem since few people who are homeless are able to participate in a census that largely relies on address (Frankish et al., 2009). Estimate places the number of homeless individuals in Canada between 150000 to 300000 (Canadian Housing and Renewal Association, 2011). It is estimated that on any given night in Canada, approximately 30000 individuals are homeless (Gaetz et al., 2013). The actual number of people experiencing homelessness is difficult to calculate as homeless individuals often reside with family or friends, also known as "couch surfing", or remain unsheltered (outside in cars, parks, or on the street) thus refrain from contacting emergency shelters (Gaetz et al., 2013). Across Canada, homelessness has gained increasing attention as structural factors like poverty, employment, and a lack of affordable housing resulted in transparency of the problem and vulnerability of the population (McLaughlin, 1987; Daly, 1989; Hwang, 2001). In Canada, homelessness has become so significant that regional and national conferences have been organized to address this issue (Coates \& McKenzie-Mohr, 2010). Such initiatives include the National Homelessness Initiative and Homelessness Partnering Strategy, Growing Home: Housing and Homelessness in Canada Conference, 2009 and Alliance to End Homelessness (Coates \& McKenzie-Mohr, 2010).

Youth have been recognized as one of the fastest growing sub-groups within the homeless population (Gaetz, Tarasuk, Dachner, \& Kirkpatrick, 2006). At any time throughout the year, as many as 65000 youth in Canada are without a home (Evenson, 2009). Youth are estimated to 
account for $20 \%$ of the homeless population in Canada and as a result of distinct needs from those which affect adults, tailored responses are required (Gaetz et al., 2013). Homeless youth have been identified as one of the most vulnerable of all populations (Gaetz et al., 2006; Dorsen, 2010). Tailoring interventions to meet the needs of this population is crucial as homelessness does not always end during adolescence; $50 \%$ of youth go on to be homeless adults (Simons \& Whitbeck, 1991; McLean, 2005).

Homeless youth are exposed to significant negative social and health challenges that serve as risks for poor social outcomes (Dawson \& Jackson, 2013). Challenges within the homeless youth population often result from inaccessibility or unavailability of support and/or services (Dorsen, 2011). Challenges include limited family support, networks of peers, adult guidance, access to health and social services, lack of education, job skills or vocational training, and a lack of financial resources. Homeless youth are at a high risk for mental health problems, such as depression and schizophrenia (Buccieri, 2013; Hughes et al., 2010). They are also at a high risk of behavioural disorders (i.e. oppositional defiant, attention deficit/hyperactivity and conduct disorders), disrupted schooling (Yu, North, LaVesser, Osborne, \& Spitznagel, 2008), physical and sexual assault, poor nutrition, inadequate shelter (Kulik et al., 2011), and an increased likelihood of engaging in risky behaviours such as tobacco, drug, and alcohol abuse (Rosenthal, Mallett, Milburn, \& Rotheram-Borus, 2008), and unsafe sex (Milburn et al., 2007). Therefore, it is evident that homelessness is clearly associated with poor health (Frankish et al., 2009; Hwang, 2001; Hwang, Tolomiczenko, Kouyoumdjian, \& Garner, 2005).

Homeless youth face many barriers that impair their access to health care services, even under the Canadian system of universal health insurance (Frankish et al., 2009). Many do not have a health card, are unable to keep appointments, and lack continuity of care due to their transience 
(i.e. no fixed address or telephone number) all adding up to their daily struggle for the essentials of life such as adequate housing, nutrition, access to health and social service providers, and treatment services (Frankish et al., 2009). The results are devastating as most marginalized homeless youth often do not receive the services they require to recover from homelessness.

It is clear that homelessness is associated with numerous adverse outcomes that extend across multiple domains of living (Edidin, Ganim, Hunter, \& Karnik, 2012). The majority of homeless youth experience a low QoL and lack the personal and social resources to successfully live independently (Krabbenborg, Boersma, \& Wolf, 2013). As adolescence is a period of marked social, psychological, and physical development (Edidin et al., 2012), the need to support homeless youth with mental health and addiction issues is crucial (Evenson, 2009). Once these issues are addressed, the health of homeless youth may become more stable (Evenson, 2009).

The research about this population is broad in scope, presenting issues of social disadvantage (Bralock et al., 2011; Commander, Davis, McCabe, \& Stanyer, 2002), pathways into homelessness (Martijn \& Sharpe, 2006; Baker, McKay, Lynn, Schlange, \& Auville, 2003), food insecurity (Tarasuk, Dachner, Poland, \& Gaetz, 2009; Booth, 2006), and mental and physical health disorders (Edidin et al., 2012; Kulik et al., 2011). In attempts to improve the lives of such a disenfranchised group, studies have aimed to improve outcomes through different treatment options for substance use and mental health problems (Guo, Slesnick, \& Feng, 2015; Thompson, McManus, \& Voss, 2006), housing options (Canada Mortgage and Housing Corporation, 2002; Tevendale, Comulada, \& Lightfoot, 2011), education opportunities (Reedvictor \& Stronge, 1997; Stronge, 1992; Sparks, 2013), and employment opportunities (BarmanAdhikari \& Rice, 2014). 
A youth's perception of their ability to recover and their current state of well-being is extremely powerful throughout the recovery process. The inability for youth to take preventative steps and recover from illness(es), is a reflection of limited social supports and social exclusion (Gaetz \& O’Grady, 2013). Supports that enable homeless youth to perceive recovery as an attainable goal facilitates resilience, hope, and the forward movement of health (Kirst, Zerger, Wise Harris, Plenert, \& Stergiopoulos, 2014; Peplau, 1952). Perceiving recovery as a realistic outcome encourages youth to adhere to treatment plans and remove themselves from the cycle of homelessness.

Despite the hardships and the many problems that homeless youth have endured, some show incredible resilience and are able to make successful transitions into adulthood (Krabbenborg et al., 2013). Resiliency, acquired through both internal factors (i.e. self-esteem and self-efficacy) and external factors (i.e. networks of support), are ultimately built through supportive relationships (Werner \& Smith, 1992; Lindsey, Kurtz, Jarvis, Williams, \& Nackerud, 2000). Peplau (1952, 1988) developed the theory of Interpersonal Relations emphasizing the importance of supportive relationships in achieving health. Supportive relationships can be created between clients and service providers, family, and peers (Peplau, 1991; Forchuk, Reynolds, Sharkey, Martin, \& Jensen, 2007). Such interpersonal relationships confirm selfworth, identity, acceptance as a human being, a sense of belonging, and other essential interpersonal needs which provide social support and reduce stress (Williams, Lindsey, Kurtz, \& Jarvis, 2001; Peplau, 1994). For example, service providers fulfill different roles with the goal of assisting the client to recognize their participatory role in health and to achieve the client's full potential. Supportive relationships have the ability to initiate the forward movement of 
personality towards productive and constructive living, ultimately improving the health of the client.

The effectiveness of supportive relationships has been studied across multiple patient populations. Previous research on supportive relationships, particularly with service providers, has predominantly focused on the treatment of adult populations. However, it is extremely relevant to the treatment and recovery of youth (Digiuseppe, Linscott, \& Jilton, 1996). Youth are often brought into treatment against their will, are rarely invested in changing their behaviour at the outset of treatment, and are difficult to engage in the therapeutic process (Kazdin, 1990; O’Malley, 1990). Therefore, constructing an effective network of supports to surround the client during recovery is seen as a crucial prerequisite to therapeutic change in the youth's overall health and regarded as a critical step in the treatment of youth (Digiuseppe et al., 1996; Meeks \& Bernet, 1990; Shirk \& Russell, 1996; Slomowitz, 1991; Peplau, 1997).

\section{Statement of the Problem}

In Canada, there is a high rate of homeless youth (Kulik et al., 2011). It is estimated that there are at least 10000 homeless youth in Toronto alone during any given year and as many as 2000 on a given night (Covenant House, 2015). Homeless youth face overwhelming degrees of challenges, stemming from psychological, physical, mental, and emotional aspects. It is estimated that the mortality rate of homeless youth is up to 40 times the mortality rate of housed youth (Covenant House, 2015). This group is extremely vulnerable and requires immediate attention as they are at a crucial point in their lives that may set them on a path into adulthood (Kulik et al., 2011).

Many youth suffer from substance abuse, mental health challenges, lack of social support, and positive role models in their life (Feng et al., 2013; Cheng, Wood, Nguyen, Kerr, \& 
DeBeck, 2014; Nyamathi et al. 2010). It is known that youth who are left unsupported frequently sink into a cycle of homelessness that extends into adulthood (Evenson, 2009). Homeless youth often report limited positive relationships with adults, characterized by abuse, betrayal, and lack of trust (Mallett, Rosenthal, \& Keys, 2005). A lack of positive relationships with an adult is linked to substance use, poor academic achievement, and poor psychosocial adjustment (Grossman \& Rhodes, 2005). Within this population, the use of services is limited as a result of multiple factors such as mistrust in individuals, ineffective services in the past, the feeling of judgement, lack of understanding, inability to access services, and perceiving recovery as an unattainable reality (Dorson, 2010; Dawson \& Jackson, 2013; Kulik et al., 2011). Further, this population often lacks authoritative figures or someone to whom they can disclose personal information. Research has demonstrated that the key to helping youth move toward the path of opportunity and out of homelessness frequently entails interventions that provide support (Evanson, 2009). Supportive relationships with an adult have been deemed a protective factor for vulnerable youth and considered constructive, helpful, and enhancing to QoL (Bartle-Haring, 2012). Networks of support have been identified as an important factor influencing a homeless youth's desire to seek help (Hudson et al., 2010; Darbyshire et al., 2006).

To improve the outcomes of homeless youth, it is crucial to comprehensively understand the connection between all aspects of the treatment process. Relationships with care providers have been associated with improved outcomes among adult populations by creating stronger interpersonal relationships, improving therapy effectiveness, and recovery status (Calsyn et al., 1999; Knuuttila, Kuusisto, Saarnio, \& Nummi, 2012; Chao, Steffen, \& Heiby, 2012). Very little research has analyzed the effectiveness of relationships with service providers and recovery 
among homeless youth. In fact, even fewer studies have analyzed the impact of size of service provider networks on perceptions of recovery, taken subjectively from the homeless youth.

Studies examining the impact of peers on the lives of homeless youth have found that peers promote the development of a caring network of support by teaching the young person how to establish healthy relationships amongst themselves and others (Kurtz, Lindsey, Jarvis, \& Nackerud, 2000; Currie \& LaBoucane-Benson, 2011; Forchuk et al., 1998). At times, homeless youth associate with peers who are involved with drugs which can lead to negative health outcomes and encourage unhealthy behaviours (Bao, Whitbeck, \& Hoyt, 2000). However, friends have also been described as providers of mutual friendship and positive role models in active decision-making and participation (Kurtz et al., 2000).

Young people largely become homeless because of challenges they experience within their families, therefore the dominant approach in Canada is to overlook the impact families can have on recovery (Winland, Gaetz, \& Patton, 2011). Familial relationships are among the more enduring and influential within a whole range of interpersonal relationships that occur through one's entire lifespan (Peplau, 1994). Maintenance of positive life cycles, characterized by feeling good, satisfaction with oneself, and having an overall positive attitude are highly correlated with good friends and supportive family relations (Helseth \& Misvaer, 2010). Self-sufficiency can be supported through reconnecting with specific family members (Winland et al., 2011; Winland, 2013).

Although the positive impact social, peer, and family support can have on homeless youth, few studies have examined the impact of these relationships on perceptions of recovery, from the perspectives of homeless youth. In addition, the majority of studies on the impact of supportive relationships on recovery are dated and may not be entirely applicable to the current 
structuring of the healthcare system, design of interventions, and population of homeless youth today. Therefore no comprehensive understanding of the effects of a spectrum of supportive relationships (i.e. size of service provider network, social supports, and family relationships) on recovery among the homeless youth population exists. Research has been lacking on interventions to meet the needs of homeless youth (Hwang et al., 2005). Given the opportunity to intervene during formative stages in the youth's life course, further work in this area is needed. For these reasons, researchers have advocated to shift to more research that explores the role of supportive relationships in the recovery of homeless youth (Auerbach, May, Stevens, \& Kiesler, 2008; Tetzlaff et al., 2005).

\section{Statement of Study Purpose}

The purpose of this study was to test Peplau's theory of Interpersonal Relations (1952) by examining the relationships among service provider network, social supports, family relations, and perceptions of recovery, from the perspective of a homeless youth. This study was a secondary analysis of data collected as part of a four year Youth Matters in London: Mental Health, Addiction and Homelessness study of homeless youth in London, Ontario (Forchuk et al., 2013). The knowledge gained from this study suggested helpful insights as to how a network of service providers, social supports, and family relations influence how a youth perceives their ability to recovery from homelessness. The information acquired may be useful to assist in the structuring of treatment and intervention plans that promote health and recovery among homeless youth. 
References

Auerbach, S. M., May, J. C., Stevens, M., \& Kiesler, D. J. (2008). The interactive role of working alliance and counselor-client interpersonal behaviors in adolescent substance abuse treatment. International Journal of Clinical and Health Psychology, 8, 617-629.

Baker, A. J., McKay, M. M., Lynn, C. J., Schlange, H., \& Auville, A. (2003). Recidivism at a shelter for adolescents: First-time versus repeat runaways. Social Work Research, 27(2), 84-93.

Bao, W.N., Whitbeck, L.B., \& Hoyt, D.R. (2000). Abuse, support, and depression among homeless and runaway youth. Journal of Health and Social Behavior, 41(4), 408-420.

Barman-Adhikari, A., \& Rice, E. (2014). Social networks as the context for understanding employment services utilization among homeless youth. Evaluation and Program Planning, 45, 90-101.

Bartle-Haring, S. (2012). The utility of mentoring homeless adolescents: A pilot study. The American Journal of Drug and Alcohol Abuse, 38(4), 350-358.

Begin, P., Casavant, L., Chenier, N. M., \& Dupuis, J. (1999). Homelessness. Ottawa:

Parliamentary Research Branch.

Booth, S. (2006). Eating rough: Food sources and acquisition practices of homeless young people in Adelaide, South Australia. Public Health Nutrition, 9(2), 212-218.

Bralock, A. R., Farr, N. B., Kay, J., Lee, M. J., Smythe-Padgham, C., Scherlin, D. D., \& Strickland, O. (2011). Issues in community-based care among homeless minorities. Journal of National Black Nurses Association, 22(1), 57-67.

Buccieri, K. (2013). Back to the future for Canada's anti-drug strategy: Homeless youth and the need for harm reduction. In S. Gaetz, B. O’Grady, K. Buccieri, J. Karabanow, \& A. Marsolais (Eds.)Youth homelessness in Canada: Implications for policy and practice (pp. 199-215). Toronto, Ontario: Canadian Homelessness Research Network

Calsyn, R. J., Morse, G. A., \& Allen, G. (1999). Predicting the helping alliance with people with a psychiatric disability. Psychiatric Rehabilitation Journal, 22(3), 283-287.

Canada Mortgage and Housing Corporation. (2002). Innovative housing for homeless youth. Ottawa: CMHC.

Canadian Housing and Renewal Association. (2011). Homelessness. Retrieved from http://www.chra-achru.ca/en/index.php/our-work/homelessness/

Chao, P., Steffen, J., \& Heiby, E. (2012). The effects of working alliance and client-clinician ethnic match on recovery status. Community Mental Health Journal, 48(1), 91-97. 
Cheng, T., Wood, E., Nguyen, P., Kerr, T., \& DeBeck, K. (2014). Increases and decreases in drug use attributed to housing status among street-involved youth in a Canadian setting. Harm Reduction Journal, 11(1), 1-6.

Coates, J., \& McKenzie-Mohr, S. (2010). Out of the frying pan, into the fire: Trauma in the lives of homeless youth prior to and during homelessness. Journal of Sociology and Social Welfare, 37, 65-96.

Commander, M., Davis, A., McCabe, A., \& Stanyer, A. (2002). A comparison of homeless and domiciled young people. Journal of Mental Health, 11(5), 557-564.

Covenant House. (2015). Facts and Stats. Retrieved from http://www.covenanthousetoronto.ca/

Currie, C., \& LaBoucane-Benson, P. (2011). Impacts of a peer support program for streetinvolved youth. Journal of Aboriginal and Indigenous Community Health, 9(1), 177-191.

Daly, G. (1989). Homelessness and health: A comparison of British, Canadian and U.S. cities. Cities, 6(1), 22-38.

Darbyshire, P., Muir-Cochrane, E., Fereday, J., Jureidini, J., \& Drummond, A. (2006). Engagement with health and social care services: Perceptions of homeless young people with mental health problems. Health \& Social Care in the Community, 14(6), 553-562.

Dawson, A., \& Jackson, D. (2013). The primary health care service experiences and needs of homeless youth: A narrative synthesis of current evidence. Contemporary Nurse: A Journal for the Australian Nursing Profession, 44(1), 62-75.

Digiuseppe, R., Linscott, J., \& Jilton, R. (1996). Developing the therapeutic alliance in childadolescent psychotherapy. Applied \& Preventive Psychology, 5, 85-100.

Dorsen, C. (2010). Vulnerability in homeless adolescents: Concept analysis. Journal of Advanced Nursing, 66(12), 2819-2827.

Edidin, J. P., Ganim, Z., Hunter, S. J., \& Karnik, N. S. (2012). The mental and physical health of homeless youth: A literature review. Child Psychiatry \& Human Development, 43(3), 354-375.

Evenson, J. (2009). Youth homelessness in Canada: The road to solutions. Raising the Roof. Retrieved from http://www.raisingtheroof.org/

Feng, C., DeBeck, K., Kerr, T., Mathias, S., Montaner, J., \& Wood, E. (2013). Homelessness independently predicts injection drug use initiation among street-involved youth in a Canadian setting. The Journal of Adolescent Health, 52(4), 499-501. 
Forchuk, C., Jewell, J., Schofield, R., Sircelj, M., \& Valledor, T. (1998). From hospital to community: Bridging therapeutic relationships. Journal of Psychiatric and Mental Health Nursing, 5(3), 197-202.

Forchuk, C., Reynolds, W., Sharkey, S., Martin, M., \& Jensen, E. (2007). Transitional discharge based on therapeutic relationships: State of the art. Archives of Psychiatric Nursing, 21(2), 80-86.

Forchuk, C., Richardson, J., Laverty, K., Bryant, M., Csiernik, R., Edwards, B., ... \& Kelly, C. (2013). Service preferences of homeless youth with mental illness: Housing first, treatment first, or both together. In S. Gaetz, B. O'Grady, K. Buccieri, J. Karabanow, \& A. Marsolais (Eds.)Youth homelessness in Canada: Implications for policy and practice (pp. 95-110). Toronto, Ontario: Canadian Homelessness Research Network

Frankish, C. J., Hwang, S. W., \& Quantz, D. (2009). The relationship between homelessness and health: An overview of research in Canada. Finding home: Policy options for addressing homelessness in Canada, 1-21.

Gaetz, S., Donaldson, J., Richter, T., \& Gulliver, T. (2013). The state of homelessness in Canada 2013. Toronto: Canadian Homelessness Research Network Press.

Gaetz, S., \& O’Grady, B. (2013). Why Don't You Just Get a Job? Homeless Youth, Social Exclusion and Employment Training. In S. Gaetz, B. O’Grady, K. Buccieri, J. Karabanow, \& A. Marsolais (Eds.) Youth homelessness in Canada: Implications for policy and practice (pp. 243-268). Toronto, Ont: Canadian Homelessness Research Network.

Gaetz, S., Tarasuk, V., Dachner, N., \& Kirkpatrick, S. (2006). "Managing" homeless youth in Toronto: Mismanaging food access and nutritional well-being. Canadian Review of Social Policy, (58), 43-61.

Guo, X., Slesnick, N., \& Feng, X. (2015). Trajectories of drug use frequency after substance abuse treatment among a sample of homeless youth. Drug and Alcohol Dependence, 146, 132.

Helseth, S., \& Misvaer, N. (2010). Adolescents' perceptions of quality of life: What it is and what matters. Journal of Clinical Nursing, 19(9-10), 1454-1461.

Hudson, A. L., Nyamathi, A., Greengold, B., Slagle, A., Koniak-Griffin, D., Khalilifard, F., \& Getzoff, D. (2010). Health-seeking challenges among homeless youth. Nursing Research, 59(3), 212-218.

Hughes, J. R., Clark, S. E., Wood, W., Cakmak, S., Cox, A., MacInnis, M., . . Broom, B. (2010). Youth homelessness: The relationships among mental health, hope, and service satisfaction. Journal of the Canadian Academy of Child and Adolescent Psychiatry, 19(4), 274-283. 
Hwang, S. (2001). Homelessness and health. Canadian Medical Association Journal, 164, 229234.

Hwang, S. W., Tolomiczenko, G., Kouyoumdjian, F. G., \& Garner, R. E. (2005). Interventions to improve the health of the homeless. American Journal of Preventive Medicine, 29(4), 311-311.

Kazdin, A. E. (1990). Premature termination from treatment among children referred for antisocial behavior. Journal of Child Psychology and Psychiatry and Allied Disciplines, $31,415-425$.

Kirst, M., Zerger, S., Wise Harris, D., Plenert, E., \& Stergiopoulos, V. (2014). The promise of recovery: Narratives of hope among homeless individuals with mental illness participating in a housing first randomised controlled trial in Toronto, Canada. BMJ Open, 4(3), 1-8.

Knuuttila, V., Kuusisto, K., Saarnio, P., \& Nummi, T. (2012). Early working alliance in outpatient substance abuse treatment: Predicting substance use frequency and client satisfaction. Clinical Psychologist, 16(3), 123.

Krabbenborg, M. A. M., Boersma, S. N., \& Wolf, J. (2013). A strengths based method for homeless youth: Effectiveness and fidelity of houvast. BMC Public Health, 13(1), 359359.

Kulik, D. M., Gaetz, S., Crowe, C., \& Ford-Jones, E. (2011). Homeless youth's overwhelming health burden: A review of the literature. Paediatrics \& Child Health, 16(6), 43-47.

Kurtz, P. D., Lindsey, E. W., Jarvis, S., \& Nackerud, L. (2000). How runaway and homeless youth navigate troubled waters: The role of formal and informal helpers. Child and Adolescent Social Work Journal, 17(5), 381-402.

Lindsey, E.W., Kurtz, P.D., Jarvis, S., Williams, N.R., \& Nackerud, L. (2000). How runaway and homeless youth navigate troubled waters: Personal strengths and resources. Child and Adolescent Social Work Journal, 17(2), 115-140.

Martijn, C., \& Sharpe, L. (2006). Pathways to youth homelessness. Social Science \& Medicine, 62(1), 1-12.

McLean, L. (2005). Seeking sanctuary: An exploration of the realities of youth homelessness in Calgary. Calgary, AB: Broadview Applied Research Group, Inc

McLaughlin, M. (1987). Homeless in Canada: Final report of the national enquiry. Ottawa, ON: Canadian Council on Social Development. 
Medlow, S., Klineberg, E., \& Steinbeck, K. (2014). The health diagnoses of homeless adolescents: A systematic review of the literature. Journal of Adolescence, 37(5), 531542.

Meeks, J. E., \& Bernet, W. (1990). The fragile alliance: An orientation to the psychiatric treatment of the adolescent (4th ed.). Malabar, FL: Krieger.

Milburn, N. G., Stein, J. A., Rice, E., Rotheram-Borus, M. J., Mallett, S., Rosenthal, D., \& Lightfoot, M. (2007). AIDS risk behaviors among American and Australian homeless youth. Journal of Social Issues, 63(3), 543-565.

Nyamathi, A., Hudson, A., Greengold, B., Slagle, A., Marfisee, M., Khalilifard, F., \& Leake, B. (2010). Correlates of substance use severity among homeless youth. Journal of Child and Adolescent Psychiatric Nursing, 23(4), 214-222.

O'Malley, F. (1990). Developing a therapeutic alliance in the hospital treatment of disturbed adolescents. Bulletin of the Menninger Clinic, 54, 13-24.

Peplau, H. E. (1952). Interpersonal relations in nursing: A conceptual frame of reference for psychodynamic nursing. New York: G. P. Putnam's Sons

Peplau, H. E. (1988). The art and science of nursing: Similarities, differences, and relations. Nursing Science Quarterly, 1(1), 8-15.

Peplau, H. E. (1991). Interpersonal relations in nursing: A conceptual frame of reference for psychodynamic nursing. New York: Springer Publishing Company.

Peplau, H. E. (1994). Quality of life: An interpersonal perspective. Nursing Science Quarterly, $7(1), 10-15$.

Peplau, H.E. (1997). Peplau's theory of interpersonal relations. Nursing Science Quarterly, 10(4), 162-167.

Reed-victor, E., \& Stronge, J. (1997). Building resiliency: Constructive directions for homeless education. Journal of Children and Poverty, 3(1), 67-91.

Rosenthal, D., Mallett, S., Milburn, N., \& Rotheram-Borus, M. J. (2008). Drug use among homeless young people in Los Angeles and Melbourne. Journal of Adolescent Health, 43(3), 296-305.

Roy, É., Haley, N., Boudreau, J. F., Leclerc, P., \& Boivin, J. F. (2009). The challenge of understanding mortality changes among street youth. Journal of Urban Health, 87, 95101.

Shirk, S. R., \& Russell, R. L. (1996). Change processes in child psychotherapy: Revitalizing treatment and research. New York: Guilford. 
Simons, R. L., \& Whitbeck, L. B. (1991). Running away during adolescence as a precursor to adult homelessness. Social Service Review, 65, 224-247.

Slomowitz, M. (1991). Adolescent psychotherapy. Washington, DC: American Psychiatric Press

Sparks, S. D. (2013). Homeless education; "Education for homeless children and youths program: Analysis of 2011-2012 federal data collection and three-year comparison". Education Week, 33(10), 5.

Statistics Canada. (2002). 2001 census: Analysis series, collective dwellings. Ottawa: Author.

Stronge, J. H. (1992). Educating homeless children and adolescents: Evaluating policy and practice. Newbury Park, California: Sage.

Tarasuk, V., Dachner, N., Poland, B., \& Gaetz, S. (2009). Food deprivation is integral to the 'hand to mouth' existence of homeless youths in Toronto. Public Health Nutrition, 12(9), 1437-1442.

Tetzlaff, B. T., Kahn, J. H., Godley, S. H., Godley, M. D., Diamond, G. S., \& Funk, R. R. (2005). Working alliance, treatment satisfaction, and patterns of posttreatment use among adolescent substance users. Psychology of Addictive Behaviors, 19, 199-207.

Tevendale, H. D., Comulada, W. S., \& Lightfoot, M. A. (2011). Finding shelter: Two-year housing trajectories among homeless youth. The Journal of Adolescent Health, 49(6), 615-620.

Thompson, S. J., McManus, H., \& Voss, T. (2006). Posttraumatic stress disorder and substance abuse among youth who are homeless: Treatment issues and implications. Brief Treatment and Crisis Intervention, 6(3), 206-217.

Werner, E.E., \& Smith, R.S. (1992). Overcoming the odds: High risk children from birth to adulthood. Ithaca, NY: Cornell University Press.

Williams, N., Jarvis, S., Kurtz, P. D., \& Lindsey, E. (2001). From trauma to resiliency: Lessons from former runaway and homeless youth. Journal of Youth Studies, 4(2), 233-253.

Winland, D. (2013). Reconnecting with Family and Community: Pathways Out of Youth Homelessness. In S. Gaetz, B. O’Grady, K. Buccieri, J. Karabanow, \& A. Marsolais (Eds.), Youth Homelessness in Canada: Implications for Policy and Practice (pp. 15-38). Toronto: Canadian Homelessness Research Network Press.

Winland, D., Gaetz, S., \& Patton, T. (2011). Family matters: Homeless youth and Eva's initiatives "family reconnect" program. Toronto: The Canadian Homelessness Research Network Press. 
Yu, M., North, C., LaVesser, P., Osborne, V., \& Spitznagel, E. (2008). A comparison study of psychiatric and behavior disorders and cognitive ability among homeless and housed children. Community Mental Health Journal, 44(1), 1-10. 


\section{Chapter Two}

\section{Background}

Perceptions of health are time-related, situation-dependent, and can vary along a continuum according to changing life circumstances. Human relationships during adolescence can be constructive or destructive influences which can alter perceptions, expectations, and behaviour patterns throughout the lifespan (Peplau, 1994). Peplau (1994) considers health a moving target, not a static state or a firm goal. Health is based on the condition of a person's life with changing circumstances.

Homeless youth, between the ages of 16-25, are considered a vulnerable, high-risk group facing a startling degree of non-normative life stressors including rejection and prejudice (Bhui, Shanahan, \& Harding, 2006; Martins, 2008), lack of affection and caring, familial conflict (Dadds, Braddock, Cuers, Elliott, \& Kelly, 1993), poverty (Zuvekas \& Hill, 2000), academic problems, lack of stable housing (Hubley et al., 2014), abuse and mental illness (Bhui et al., 2006; Martinez et al., 1998), and substance use (Johnson, Freels, Parsons, \& Vangeest, 1997). The literature is consistent in stating that homeless individuals tend to have poorer health than those who are housed (Hwang, 2001; Cheung \& Hwang, 2004; Palepu, Hubley, Russell, Gadermann, \& Chinni, 2012; Larson, 2002; Riley et al., 2003; Evans \& Huxley, 2002; Cummins, 1995). Many studies demonstrate that homeless individuals are also at a higher risk of experiencing compromised mental health and mental illness than the general public resulting in lower levels of health (Hwang, 2000, 2001; Feng et al., 2013; Cheng, Wood, Nguyen, Kerr, \& DeBack, 2014).

Recovery is a complex yet increasingly appreciated and insightful concept, especially in the fields of mental health and substance abuse (Davidson \& White, 2007; Deegan, 1988; Essock 
\& Sederer, 2009; Harvey \& Bellack, 2009; Holloway, 2008; Mountain \& Shah, 2008). This analysis will utilize the ideology of recovery grounded in the subjective experiences and aspirations of those directly affected by the illness itself (Deegan, 1988; Anthony, 1993; Barbic, Krupa, \& Armstrong, 2009). The Substance Abuse and Mental Health Services Administration (SAMHSA, 2014) defines recovery as a highly individualized and personal process of change through which individuals improve their health and wellness, live self-directed lives, and strive to reach their full potential. In SAMHSA's (2006) consensus statement on recovery, recovery is described as functional remission which focuses on one's ability to reclaim/claim full and meaningful life in the community.

Quality of life (QoL) is often associated with health and a key indicator of recovery (Peplau, 1994; Corrigan, Giffort, Rashid, Leary, \& Okeke, 1999). Other conceptualizations of recovery emphasize various concepts including self-agency (Abbott, 2008; Rogers, Chamberlin, Ellison, \& Crean, 1997; Mancini, 2008), self-esteem and self-respect (Jacobson \& Greenley, 2001; Werner \& Smith, 1992), and hope and optimism about the future (Kirst, Zerger, Wise Harris, Plenert, \& Stergiopoulos, 2014). Therefore, it is clear that the capacity for growth and recovery is a multifaceted, innate ability to human beings (Krabbenborg et al., 2013; Peplau, 1994). Homeless youth can initiate the process of recovery by exploring their inherent strengths and aspirations (Krabbenborg et al., 2013). Supportive relationships are the crux to enabling one to recognize innate strengths to make recovery a realistic goal.

Engaging homeless youth into reintegration services is a priority (Banchevska et al., 2011; Gaetz, 2004). The interpersonal relationships with service providers facilitate reintegration as it assists clients in coping with passages from one life situation to another (Peplau, 1997). During these transition periods, relationships with service providers present the client with a 
"resource person" who has the information to instruct clients as they move from a familiar situation (i.e. homelessness, substance use, etc.) to an unfamiliar one (i.e. housing, treatment plans, etc.) (Peplau, 1997). A resource person reduces the uncertainty and stress for the client during moments of transition enabling better coping. The impact of a positive relationship with an adult has been deemed a protective factor for vulnerable youth, expected to be constructive, helpful, and enhancing to overall health and recovery (Krabbenborg et al., 2013; Bartle-Haring, 2012; Peplau, 1994).

Homeless youth tend to experience unstable social support networks (Landowne, 2011). Street youth have reduced links to networks of peers and social supports that can be used to get ahead (Karabanow \& Naylor, 2010, 2013). Social support is often defined through structural supports and is a measure of integration through social networks (Hogan, 2002) created through marriage, friendship ties, and group and organization membership (Cohen, 2003; Uchino, 2004). In this study, social support referred to the relationships the homeless youth have with people they see socially, such as friends. Social support has the ability to mitigate negative and stressful life events within the lives of homeless youth (Krabbenborg et al., 2013; Forchuk, 1991). For many youth, friends are sources of protection and support (Kurtz et al., 2000; Martijn \& Sharpe, 2006; Nyamathi et al., 2010; Park, Kim, Kim, \& Sung, 2007). Increased social supports have been associated with better physical and mental health, improved self-esteem, self-confidence, social skills, and coping abilities. Therefore, social support has been considered crucial for illness recovery in mental health (Stewart, Reutter, Letourneau, \& Makwarimba, 2009; Unger et al., 1998; Kidd \& Shahar, 2008).

Familial relationships (i.e. parents, siblings, grandparents, and significant caretakers) have an enormous influence on the developmental years and in shaping behaviours of children 
(Peplau, 1994). Family relationships develop between whoever the family defines as a member (Forchuk et al., 1998). Academic research consistently identifies difficult family situations and conflict as being the key underlying factors in youth homelessness (Morrell- Bellai, Goering, Boydell, 2000; Reid, Berman, \& Forchuk, 2005; Rew, Taylor-Seehafer, \& Fitzgerald, 2001). Therefore, many services assume that because young people are fleeing damaged family situations, they must leave their family behind to move on. As a result, the dominant approach to working with homeless youth in Canada is to ignore the potential role of family members (Winland, 2013). However, some research has demonstrated that if family ties can be reconstructed and particular family members can be reconnected, family members can be crucial support figures in the youth's transition into adulthood and throughout recovery (Kurtz et al., 2000; Winland, 2011).

\section{Theoretical Framework}

This study was guided by Peplau's theory of Interpersonal Relations (Figure 1). Peplau's theory $(1952,1992)$ provides a conceptual framework by which a nurse may assess, plan, and intervene during care for optimal client outcomes. Peplau's (1991) theory emphasizes that nurses are key to fostering the therapeutic environment. Within this therapeutic environment, clients learn adaptive interaction, coping, and relationship skills that they can generalize to other aspects of their life to improve their health (Kuhns, 2007; Peplau, 1991). Peplau's $(1952,1991)$ theory evolved through educational endeavors and a desire to achieve better outcomes for clients.

Although Peplau's theory primarily focused on the therapeutic nurse-client relationship between nurses and psychiatric clients, it has been extended through participatory action research including health care consumers, nurses, and other disciplines (Forchuk et al., 1998). As a result of its progression, the foundation of the approach is the development of a supportive network of 
interpersonal relationships (Forchuk et al., 1998). Such relationships extend beyond the nurseclient relationship and include interpersonal relationships with other health and service providers, family members, trusted individuals, and peers (Peplau, 1991; Forchuk et al., 1998; Forchuk, Reynolds, Sharkey, Martin, \& Jensen, 2007). Individuals are believed to heal in supportive relationships therefore a network of relationships that the client trusts and can consult with are crucial to the client's success (Forchuk et al., 2007; Peplau, 1997; Peplau, 1994).

Peplau's theory consists of the interrelation of many concepts and sub-concepts. The relationship is initiated with a change in the health status of a client (Peplau, 1992). It is believed that a network of supportive relationships can be the most beneficial to the growth of human beings as they confirm self-worth, support, and esteem (Peplau, 1992, 1994, 1997). Interpersonal relationships, encompassing interaction, communication, and support, are influential factors in the outcomes for clients (Peplau, 1952; Forchuk, 1991). The major concepts in Peplau's theory of Interpersonal Relations are described and defined below. The theory is depicted in Figure 1: Peplau's Framework: Major Concepts and Their Inter-Relationships.

1. Nursing "aims to promote forward movement of the personality in the direction of creative, constructive, productive, personal, and community living" (Peplau, 1952, p. 16; Peplau, 1992).

2. Nurse-client relationships are the specific relationships that develop between nurses and clients with the primary goal to promote health through interpersonal, problem solving, and community living skills (Peplau, 1997; Forchuk et al., 1998).

3. Interpersonal relations relate to any processes that may occur between two or more individuals (includes the nurse-client relationship and other interpersonal relationships) (Forchuk, 1991; Peplau, 1987). 
a) Family relationships that develop between members of a family are normally created by commitment (i.e. marriage, common ancestors or descendants)

(Forchuk et al., 1998). Family includes whoever the family defines as a member.

b) Peer relationships are created between people as a result of common attributes or life experiences (Forchuk et al., 1998). They develop individually through friends or through groups, such as support networks or self-help groups.

4. Client refers to "sick and well individuals, groups, and communities for whom the nurses provide direct nursing services" (Peplau, 1988, p. 9).

Figure 1: Peplau's Framework: Major Concepts and Their Inter-Relationships (Forchuk, 1991).

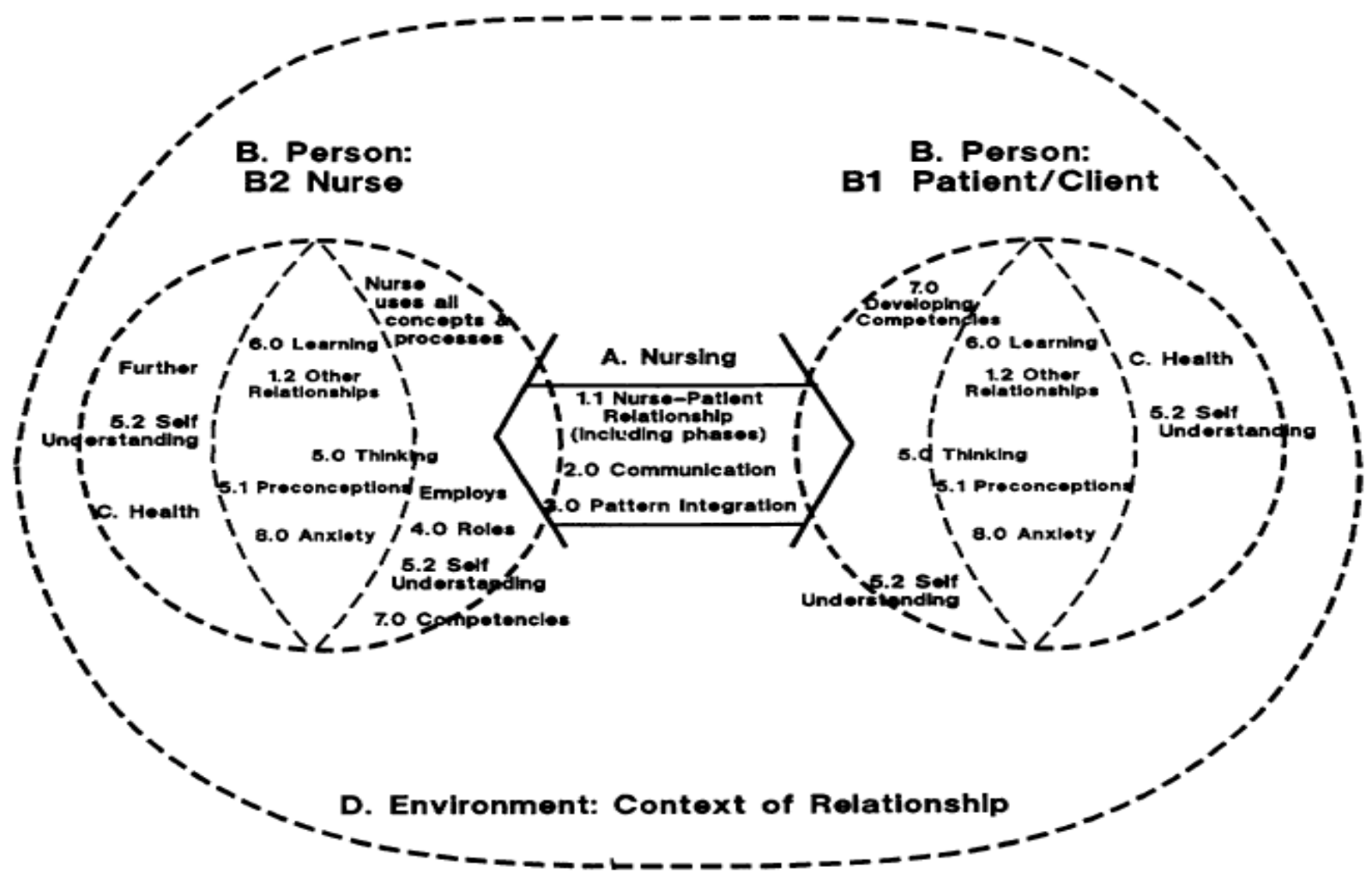

5. Health, being the primary goal of the relationship , "implies the forward movement of personality and other on-going human processes in the direction of creative, constructive, personal, and community living" (Peplau, 1952, p. 12). 
6. Environment includes physiological, psychological and social elements that can be potentially illness maintaining or health promoting (Peplau, 1952; Forchuk, 1991).

\section{Review of the Literature}

The review of the literature explores the variables used in this analysis to represent health, the forward movement of personality, and interpersonal relationships. The concepts examined in the literature review include: Perceptions of Recovery, Service Provider Network, Social Supports, and Familial Relationships.

Nursing, health, medicine, and psychology based databases were analyzed. Databases included CINAHL, Proquest Nursing Journals, Medline, Pubmed and PsychINFO. The search included peer-reviewed, scholarly articles, and grey literature composed in the English language. All searches included key words: "Homeless" and "Youth". The first search included additional key words: "Recovery", "Social support", "Family", and "Service Provider”. Databases produced no results. "Recovery" was searched alone and yielded no relevant studies therefore, “QoL" was added as an "and/or" term. Databases produced 23 sources and upon review three were relevant to this study. The additional key words were searched separately yielding a total of 15 relatively relevant studies. A total of 18 studies with moderate to high relevancy to this study were found. Relevance was determined by examining the abstracts for concepts related to peer or other forms of social support, some extent of family relationships and supportive relationships with either an adult, mentor, or health and/or social service provider. The reference lists of all relevant studies were reviewed to explore related literature in the subject area.

\section{Perceptions of Recovery}

Studies have examined the health and well-being of homeless youth. In an exploratory study by Hwang et al. (2010), the extent of barriers to accessing health care among homeless 
individuals in Toronto, Ontario was examined. Findings from the study indicated that younger age was associated with an increased likelihood of unmet physical, mental, alcohol and drug needs. Although this study did not primarily focus on youth or how they perceive their recovery, it reinforces the level of health disadvantage facing the homeless youth population today. Given the multifaceted issues facing homeless youth, recovery is a concept that must be further explored in the literature.

Bearsley and Cummins (1999) compared the QoL in homeless and housed (living with their families) youth in a sample of 524 youth ranging from ages 14-17 in Melbourne, Australia. Homeless youth reported significantly lower QoL, along with lower levels of personal meaning, intimacy with family, emotional wellbeing, safety, and sense of belonging. Findings indicated that homeless youth are at a high risk of experiencing lower levels of intrapersonal and interpersonal skills, concepts closely related to recovery. Although this study focused on QoL, it was included in this literature review as it reinforces that homeless youth report low levels of interpersonal and intrapersonal skills necessary to recover. More recent studies, reflecting the new generation of homeless youth are needed to address the impact of interpersonal relations on recovery.

In a qualitative phenomenological study by Lindsey et al. (2000), 12 homeless youth from Georgia and North Carolina, between the ages 18-25 were interviewed regarding their methods of living in high-risk environments and transitioning into adulthood. Two dimensions of successful living emerged: personal strengths and resources (i.e. self- confidence, self-love, taking responsibility for own actions, and avoiding bad influences) and help received from others (i.e. getting along with others and trusting and accepting help from others). This study reinforces the importance of interpersonal and intrapersonal relationships in the successful transition from 
youth to adulthood. Different types of interpersonal relationships were not examined leaving a limited understanding of important relationships in the recovery of homeless youth. Therefore, it is important that future studies examine the impact of various interpersonal relationships on all dimensions of recovery.

The literature is extremely limited regarding homeless youth and aspects that contribute to their perceptions of recovery. Literature has identified the importance of interpersonal relationships and intrapersonal skills on aspects of recovery. However, no conclusive understanding of the impact of various interpersonal relationships on homeless youth recovery exists. In addition, no studies have examined the correlation of various interpersonal relationships among all dimensions of recovery. Therefore, this study was designed to address this gap.

\section{Service Provider Network}

Despite the lack of literature available on evidence-based interventions with health and social service providers, research indicates that a positive relationship with an adult may be a protective factor for vulnerable youth (Rolf et al., 1990). In a study by Bartle-Haring (2012), the impact of mentoring among homeless youth aged 14-20 years, receiving substance use treatment from trained mentors was examined in the United States. Findings indicated that mentoring with treatment was associated with a decrease in problems associated with substance use. In a study by Grossman and Rhodes (2002), the effects of youth mentor relationships were examined in a sample of 1138 young, urban youth in the Big Brothers Big Sisters program, in the United States. Relationships that lasted at least one year were associated with improvements in the youth's academic, psychosocial, and behavioural outcomes. Relationships that terminated within three months resulted in reductions in the youth's self-worth, perceived scholastic competence, and 
increases in alcohol use. Although the youth were not homeless, it is evident that positive supportive relationships with adults can improve outcomes across multiple domains. Both studies reinforce that supportive relationships with an adult mentor may improve outcomes in substance use and self-esteem however such relationships may differ from those with service providers. A gap remains in our understanding of such relationships on homeless youth's perceptions of recovery.

Though scarce, some literature indicates that relationships with service providers are crucial in effective interventions among homeless youth. A pilot study by McCay et al. (2011) evaluated the impact of relationship-based interventions for homeless youth receiving services from agencies in Toronto. Fifteen participants, aged 16 to 24 underwent six sessions with a clinician focusing on social support, social networks, positive self-concepts, and resilience. Participants who received the intervention experienced improvements in social connectedness and decreased hopelessness and those that did not experienced increased levels of mental health symptoms. The role of the clinician was not specified however, the findings suggest that supportive relationships with service providers may strengthen homeless youth's social relationships and mitigate overwhelming hopelessness and despair. A gap still remains in our understanding of the impact of multiple relationships with service providers on homeless youth's perceptions of recovery.

It is evident from the literature that relationships with adults, through mentorship programs or service providers, are important in the health and recovery of homeless youth. However, the majority of research examines the relationship between a single provider and specific outcomes, primarily mental health issues, reductions in substance use, and psychosocial improvements (Krabbenborg et al., 2013; Slesnick et al., 2009). No present studies have 
examined the correlation between number of service providers and perceptions of recovery, let alone from the perspectives of the homeless youth themselves. This study was designed to address this gap.

\section{Social Support}

Social support, including peer relationships are essential supports for street youth (Karabanow \& Clement, 2004). For example, Unger et al. (1998) analyzed the effects of stress, coping, and social support on symptoms of depression, poor physical health, and substance use among 432 homeless youth between the ages of 13-24 in California. Social support reduced the risk of depression and poor health. This indicates that effective coping and social support may counteract the negative effects that stressful life events have on homeless youth's physical and psychological health. Similar outcomes were found in a study by Kurtz et al. (2000) examining the impact of formal and informal helping resources to resolve difficulties and achieve selfdefined success in life. Among the sample of 12 homeless youth, aged 18-25 years in North Carolina and Georgia, three quarters commented on the importance of friends. Friends were said to be sources of unconditional support, valued confidants, and even chosen family members. At times, they provided motivation needed for change. The importance of social and peer supports among homeless youth was reinforced in both studies, however participants were living in the United States and may be subjected to different challenges than those living in Canada. Although both studies presented outcomes that relate to recovery, i.e. mental health, depression, and motivation to change, recovery as a whole was not examined. Finally, both studies are dated and may not be entirely applicable to the generation of homeless youth today. For these reasons, it is important to examine the present impact of social supports on Canadian homeless youth's perception of recovery. 
In a study by Kidd (2003), qualitative analysis was used to examine negative and positive experiences with social support in a sample of 80 street youth, under the age of 25 . The study sites included Toronto and Vancouver. Participants described their friends as "street family" and invaluable in teaching them how to cope with street life. Support was described as emotional, and in terms of money and safety. In another Canadian study, in Edmonton, by Currie and LaBoucane-Benson (2011), the impact of the Links program, a peer support program for street youth, was examined. Participants consisted of 27 homeless youth aged 18-26 years and 28 university students that held group discussions and bonded with the homeless youth. The program enabled the youth to develop communication and interpersonal skills, overcome fears of rejection, and form strong bonds. Both studies described above underscore the importance of peer support in coping with homelessness and its impact on interpersonal and intrapersonal skills related to recovery. A gap remains in our understanding of how peer support influences subjective perceptions of recovery as a whole.

The impact of peers and other social supports have been examined in the literature. Homeless youth are not a homogeneous group (Hughes et al., 2010; Carlson et al., 2006) therefore literature relevant to the current generation of homeless youth in Canada is needed. Elements of recovery have been independently examined in studies however very few studies have examined the impact of supportive and peer relationships on a homeless youth's subjective perceptions of recovery as a whole. This study was designed to address this gap.

\section{Family Relations}

Reconnecting homeless youth with family may be important in securing an environment of supportive relationships necessary in the process of recovery (Winland, 2013). In a study by Hughes et al. (2010), mental health, hope, and service satisfaction was examined among a 
sample of 60 homeless youth, aged 16-24, who accessed an overnight shelter in Halifax, Nova Scotia. Participants reported leaving home because of trauma (family conflict and/or violence) and intolerable conditions but the majority maintained regular contact with some family members. Older participants viewed their familial relationships more positively suggesting that developmental stage may influence family upheaval. This study indicated that many homeless youth maintain contact with some family members, even sustaining positive relationships. Therefore, specific family members can potentially be integrated throughout intervention approaches.

Winland et al. (2011) created a program titled Eva's Reconnect Program in Toronto offering homeless youth, aged of 16-24, opportunities to rebuild relationships with family. Participants underwent individual and family therapy guided by counselors and therapists. Between 2005 to 2010, Eva's program provided care for 376 clients, of which the majority (69\%) maintain active involvement with some family members. Although family members were not specified, during the program, $62 \%$ of participants became more involved with family, $14.5 \%$ reconciled a damaged relationship with a family member, and $17 \%$ moved back home with their family. It is evident that for some homeless youth, specific family ties can be reconstructed and those members may be integrated into treatment plans. However, our understanding of the impact of family relations on a homeless youth's perceptions of recovery remains limited.

Although not examining homeless youth, Werner and Smith's (1992) longitudinal study of more than 200 children living in poverty in Kauai, Hawaii reinforce the importance of family relations. When families portrayed warmth, affection, emotional support, and structure children exhibited a high level of resiliency. In troubled families, resilient children often formed 
attachments to other influential adults in their life. Research on resilient children and youth has shown that in the event a parent is incapable to raise a child, other significant people can play a role (i.e. grandparents, siblings, or care-providers) (Smith, 2000; Krabbenborg et al., 2013). Therefore, understanding that intrapersonal aspects of recovery are nurtured through family relations in poverty stricken children, there is a need to study the impact of family relations on homeless youth's recovery. Further, in the study described above by Kurtz et al. (2000), the impact of formal and informal helping resources were examined. Findings indicate that despite the volatility in family relations, homeless youth reported that some of their family members were sources of caring and support at critical times in their lives. Family members, including siblings, grandparents, aunts, and uncles also provided emotional support and encouragement during difficult times. Therefore, it is evident that some family relations can be utilized to provide support however, our understanding of such relationships on a youth's perception of recovery remains limited.

It is evident that family can provide the crucial support needed in a homeless youth's transition period (Hughes et al., 2010; Kurtz et al., 2000; Winland et al., 2011). Studies have analyzed how familial relations relate to various aspects of recovery, predominately intrapersonal concepts among populations other than homeless youth. However, no relevant studies analyzing the relationships between family relations and perceptions of recovery exist in the homeless youth population. This study was designed to address this gap.

\section{Hypotheses and Rationale}

Based on Peplau's $(1991,1992)$ theory of Interpersonal Relations and a review of the literature, the following hypotheses were developed (Figure 2): 
1. A larger network of service providers will be positively correlated to higher levels of perceived recovery.

2. Higher levels of perceived social support will be positively correlated to higher levels of perceived recovery.

3. Higher levels of perceived family relationships will be positively correlated to higher levels of perceived recovery.

4. A larger network of service providers, higher levels of perceived social support, and higher levels of perceived family relations will result in higher levels of perceptions of recovery.

According to Peplau (1992, 1994), individuals heal in supportive relationships. Peplau $(1991,1997)$ identifies the interpersonal relationship as an essential component in the forward movement of personality, and attainment of a higher level of health. Supportive relationships can be created between service providers, family, peers, and other individuals that the client interacts with (Forchuk et al., 2007). The relationship encourages the development of intrapersonal and interpersonal skills that are crucial in the progression of health and the process of recovery.

Peplau (1997) discusses the importance of service providers in reintegrating clients coping with life transitions. Service providers are resource people that assist homeless youth in acquiring skills and competencies needed throughout recovery (Moran et al., 2014). A larger network of service providers with individual skills and knowledge would be expected to positively impact the recovery of homeless youth. Social supports, such as peers, and familial relations are also important in the development of intrapersonal and interpersonal skills (Winland et al., 2011; Karabanow \& Clement, 2004; Peplau, 1997). Peers promote a caring network of support that the youth can relate to, providing motivational and decision-making support that 
encourages participation in recovery interventions (Kidd, 2003). Familial relations are important in the development of self-sufficiency and resiliency needed to make positive changes in the lives of homeless youth (Winland et al., 2011; Peplau, 1994). Therefore, it is expected that high levels of social support and family relations would be positively associated with a homeless youth's perceptions of their ability to recover.

\section{Methods}

\section{Design}

A predictive non-experimental design was used (Kellar \& Kelvin, 2013). This study was a secondary analysis and used data collected as part of the Youth Matters in London: Mental Health, Addiction and Homelessness study (Forchuk et al., 2013). Approval for the larger study was obtained from the University of Western Ontario's research ethics board for Health Sciences Research Involving Human Subjects, and participants consented to having their data used for secondary analysis.

\section{Sample}

In the original Youth Matters Study conducted by Forchuk et al. (2013), the participants were obtained through convenience sampling, a non-probability sampling technique (Kellar \& Kelvin, 2013). Participants were recruited from local drop-in centres, shelters, service agencies, snowballing, and word of mouth in the London-Middlesex area. The sample consisted of 187 youth between the ages of 16-25 who were homeless at the time of their enrollment. This age range was selected as it is compatible with the majority of pre-existing studies on homeless youth, and the criteria of homeless programs serving youth within the region. For the purposes of the Youth Matters study, homeless referred to anyone living on the streets, in shelters, or precariously housed. Interviews with participants were conducted at six month intervals over a 2.5 year period. Interviews were approximately one hour in length and participants were 
compensated \$20.00 for their participation and time. Informed consent was obtained in writing prior to interviewing.

This study used a subsample of the original Youth Matters study (Forchuk et al., 2013). Demographic data was re-coded to fit the statistical analysis required therefore demographic variables may differ slightly from those in the original study. In addition, some demographic variables were re-coded into dichotomous variables. Variables recoded into dichotomous variables include: sex, marital status, children, and substance use. Sex was re-coded into either 'male' or 'female' as $98.4 \%$ of the sample population identified with one of these categories. The three participants that assigned themselves with another sexual identity were excluded. Marital status was re-coded into either 'single' or 'other' (cohabitating with partner, married, or separated). 'Number of children' was re-coded into either 'no children' or 'one or more child/children' (one to four or more children). Substance use was re-coded into having engaged in substance use within the past year (past month or 2-12 months ago) or other (over a year ago or never). Variables were re-coded into dichotomous variables after examining the data from the original sample to determine if significant variability was present among any of the demographic categories. The variables were then re-coded to represent how the majority of the participants responded to the questions.

For this secondary analysis, the G*Power 3.1 computer program was used to calculate sample size (Cohen, 1988). A post hoc sample calculation was conducted based on a statistical significance level of 0.05 , a power 0.8 , and a medium effect size of 0.15 . Approximately 77 subjects would be needed for this regression analysis with three independent variables and one dependent variable (Faul, Erdfelder, Buchner, \& Lang, 2009). Therefore, the sample had adequate power to test the stated hypotheses. 


\section{Instrumentation}

Data used in this secondary analysis was collected using two standardized self-report instruments as well as a derived variable to measure the major study variables.

Perceptions of Recovery. Perceptions of recovery was measured using the Recovery Assessment Scale (RAS). The RAS is a measurement tool used to determine the recovery status, defined as living a satisfying life within the constraints of a mental illness (Deegan 1988, 1996; Leete 1989; Unzicker 1989; Anthony 1993; Hogan 2003). The work by Giffort, Schmook, Woody, Vollendorf, and Gervain (1995), combining participatory action research and narrative analysis generated 39 items to represent the construct of recovery. After review by an independent group of consumers, the scale was refined and is now a 41 -item instrument (Corrigan, Salzer, Ralph, Sangster, \& Keck, 2004). A shorter, 24-item version of the RAS also exists. The RAS is measured using a 5-point Likert scale (1- do not agree at all to 5- very much agree) and tests for empowerment, coping ability, and QoL (Giffort et al., 1995).

Several studies support the psychometric properties of the RAS. A study by Corrigan et al., 1999) aimed to examine the psychometric characteristics of the RAS in a sample of 35 participants with a severe mental illness in a partial hospitalization program. Participants were evaluated on two occasions, 14 days apart. To assess the concurrent validity, the researchers used eight additional instruments measuring QoL, social support, self-esteem, empowerment, psychiatric symptoms, needs and resources, global functioning, and verbal intelligence. The RAS showed recovery to be positively associated with self-esteem, empowerment, social support, and QoL. Overall, findings from this study indicate that the RAS has good test-retest reliability $(\mathrm{r}=.088)$ and good internal consistency (Cronbach alpha= 0.93). 
Corrigan et al. (2004) also conducted a factor analysis of the RAS and found five factors comprising the 24 items. Factors identified in the study were: personal confidence and hope, willingness to ask for help, goal and success orientation, reliance on others, and symptom coping. These findings are similar to other components of recovery reported in previous conceptual studies (Young \& Ensing, 1999; Spaniol, Wewiorski, Gagne, \& Anthony, 2002; Ralph, 2000) indicating that this tool has good construct validity for assessing the recovery processes. These findings were replicated in another study by McNaught, Caputi, Oades, and Deane (2007) examining the exploratory and confirmatory factor analyses of the RAS. Participants consisted of 168 individuals with severe and persistent psychiatric disabilities. The items loading on the five factors were highly consistent with those identified by Corrigan et al. (2004). All factors demonstrated satisfactory internal reliability (Cronbach's alpha range $=0.73$ 0.91). The factors displayed significant correlations with other recovery measures establishing convergent validity. Concurrent validity was demonstrated with significant but lower correlations with symptoms and clinician-rated measures of psychiatric functioning (participants completed self-report recovery and other mental health measures and case workers completed some of the Australian routine outcome assessment measures, e.g. Health of the Nation Outcome Scales). Overall, the RAS has proven to be a valid measure in psychiatric populations with solid psychometric and conceptual features that make it useful in mental health services research (Corrigan et al., 2004; McNaught et al., 2007).

Service Provider Network. To measure Service Provider Network, the researcher created a derived variable from the "Health, Social, Justice Service Use" questionnaire used in the Youth Matters study (Forchuk et al., 2013). The derived variable was created to measure the extent of access that the homeless participants received with service providers. Access referred to 
contact made with the service providers at the providers office, over the phone, or visits made by the provider at the youth's home or location of choice. Service provider referred to anyone that the participant had seen for health concerns or assistance in daily life. Service providers in the study included: health providers (doctor, nurse, or psychiatrist), housing workers, social workers, justice workers, probation officers, etc. All service providers were considered for the analysis as the recovery process for homeless youth must be multifaceted and involve interventions that extend across multiple domains of life (Slesnick et al., 2009; Palepu et al., 2012). Questions on the measure included: "In the past month, have you seen a health or social services provider at his or her office", "Who else have visited at their office this past month?", "This past month, have you talked on the phone about your health, housing, or other needs with a health or social services provider?", "In the past month, have you been visited by a health or social service provider at your home or anywhere else?". The questionnaire collected responses for up to a maximum of ten points of access with service providers. Therefore, the derived variable was a continuous variable ranging from zero to ten contacts with service providers.

Social Support and Family Relations. Social support and family relations were assessed using subscales from the larger QoL Interview-20 (QOLI-20), which was developed from the original 143-item QOLI (Uttaro \& Lehman, 1999; Lehman, 1996). The original QOLI is a structured self-report interview that was designed to assess the QoL of people with severe and persistent mental illness. It assesses what the participant actually experiences ("objective" QOL) and their feelings about these experiences ("subjective" QOL) (Lehman, Ward, \& Linn, 1982). The psychometric properties of the original QOLI have been extensively examined. Internal consistency reliabilities range from $0.79-0.88$ for the life satisfaction subscales and from 0.440.82 for the objective subscales (Lehman, 1996). Cronbach alpha coefficients for the seven 
subjective subscales were: living situation (0.83), everyday activities (0.83), family relations $(0.88)$, social relations $(0.71)$, finances $(0.84)$, safety $(0.84)$, and satisfaction with life in general (0.74). Objective subscale alpha coefficients were: everyday activities (0.62), enough money (0.78), family contacts (0.69), and contacts with friends (0.72) (Lehman, 1996). Items on the measure are scored on seven-point ordered Likert scale ranging from "terrible" to "delighted". Over the past 10 years, it has undergone a variety of revisions to improve its psychometric properties and make it shorter. These reliabilities have been replicated in studies of individuals suffering from mental illnesses (Lehman, 1996). Test-retest reliabilities have been assessed after one week for the life satisfaction scales (0.41-0.95) and objective subscales (0.29-0.98). Confirmatory factor analysis and multivariate predictive models established construct and predictive validity. The QOLI also differentiates between hospitalized clients and those in supervised community residential programs (Lehman, Possidente, \& Hawker, 1986; Simpson, Hyde, \& Faragher, 1989).

A 35-item version of the QOLI called the QoL-Short Form (QL-SF) was developed by Lehman (1988) in a self-response format. Preliminary studies support the QL-SF's internal consistency and validity compared to the QOLI (Lehman, 1988; Uttaro \& Lehman, 1999). The QOLI-20 is a 20-item measure, developed from the 35 -item interview by Uttaro and Lehman (1999) using item-response theory (IRT). IRT resulted in 20 subjective items that retain the internal consistency of the original scale. The coefficient alpha for the QOLI-20 was 0.900 . The QOLI-20 consists of six subscales: family relations, finances, leisure, living situation, safety, and social support as well as a global item assessing the individual's overall satisfaction with life. Items are rated on seven-point Likert scale, ranging from 1-“terrible" to 7-“delighted". In addition, "do not know" or "declined" were also possible responses. 
Demographic variables. Relevant demographic information were included from the "Demographic, Service \& Housing History" and "GAIN-SPS" questionnaires used in the Youth Matters study to obtain a descriptive understanding of the sample (Forchuk et al., 2013).

Demographic information used from the questionnaires in this regression analysis included: sex, age, marital status, children, drug use in the past year, and self-reports of mental disorders.

\section{Data Analysis}

Statistical analysis was conducted using the Statistical Package for Social Sciences (SPSS) program, version 20.0 (IBM Corporation, 2013). In order to adhere to underlying statistical assumptions, data distributions were analyzed prior to the main analysis. Descriptive statistics were performed on all variables and hierarchical multiple regression analysis was used to test the hypotheses. Statistical analyses included ANOVA, t-tests, and Pearson correlation coefficients to examine the relationships between the demographic variables and the main study variables.

\section{Results}

\section{Participant Characteristics}

Demographic characteristics are presented in Table 1. The average age of participants was $20.9(M=20.92, \mathrm{SD}=2.450)$ years of age. The majority were male $(66.3 \%)$, single $(79.3 \%)$, and had no children (71.2\%). Most participants reported engaging in drug use (91.8\%) in the past year and reported having a mental disorder (96.2\%). These findings are consistent throughout the literature stating that homeless youth have an extremely high likelihood of engaging in substance use and reported mental health issues (Feng et al., 2013; Evanson, 2009).

\section{Descriptive Results}

The means and standard deviations along with reliability statistics and correlations for the 
study variables are found in Table 2 . The network of service providers that the sample of homeless youth utilized was extremely small $(M=0.97, S D=1.03)$. Of the QOLI-20 subscales, social supports had the highest rating. Homeless youth perceived themselves as having a moderately high levels of social supports in their life $(M=4.9, S D=1.14)$.

Within the sample, participants reported a moderate level of satisfaction with their current familial relationships $(M=3.8, S D=1.5)$. Regarding the subscales of perceptions of recovery, goal and success orientation had the highest rating $(M=4.05, S D=0.685)$, followed by personal confidence and hope $(M=3.84, S D=0.670)$, and reliance on others $(M=3.83, S D=0.794)$. Willingness to ask for help $(M=3.59, S D=0.927)$ and not dominated by symptoms $(M=3.08$, $S D=1.00)$ were rated as the lowest among the subscales.

Table 1: Description of demographic characteristics of homeless youth

\begin{tabular}{|l|l|l|}
\hline \multicolumn{2}{|l|}{$n$} & $\%$ \\
\hline Sex & 62 & 33.6 \\
\hline Female & 122 & 66.3 \\
\hline Male & 146 & 79.3 \\
\hline Marital Status & 38 & 20.7 \\
\hline Single & $\begin{array}{l} \\
\text { Other (cohabitating with } \\
\text { partner, married, } \\
\text { separated) }\end{array}$ \\
\hline Children & \multicolumn{2}{|l|}{} \\
\hline No children & 131 & 71.2 \\
\hline More than 1 child & 53 & 28.8 \\
\hline Drug Use & 169 & 91.8 \\
\hline Past year & 15 & 8.2 \\
\hline $\begin{array}{l}\text { Other (never/>1 year } \\
\text { ago) }\end{array}$ & \multicolumn{2}{|l|}{} \\
\hline Mental disorder & 177 & 96.2 \\
\hline Yes & 7 & 3.8 \\
\hline Unknown &
\end{tabular}

$M$, mean; $S D$, standard deviation; $n$, number

As a whole, the homeless youth's reports of their perceptions of recovery and recovery status were to the positive end of the scale $(M=3.7, S D=0.58)$. In this study, the reliability coefficients 
for the perceptions of recovery scale (Cronbach alpha: 0.88 ), the social support subscale (Cronbach alpha: 0.77) and family relations subscale (Cronbach alpha: 0.84) are acceptable $(>0.70)$.

\section{Relationships of Demographic Variables to Major Study Variables}

To address the influence of demographic variables on the hypothesized relationships, several demographic variables were analyzed for potential associations among the main study variables. The demographic variables analyzed included: age, sex, marital status, children, drug use, and self-reported mental disorders. As very little variation was present within the majority of the demographic variables examined, most did not present statistically significant differences in the means of both groups. The only demographic variable that was significantly related to any of the major study variables was sex on service provider network. There was a significant difference in the mean scores for male $(M=0.58, S D=0.702)$ and female $(M=0.97, S D=1.145)$ participants $(t=-2.431, \mathrm{p}=.017)$.

\section{Correlations among Study Variables}

A correlational analysis was conducted to examine the interrelationships among service provider network, social support, family relations, and the subscales of perceptions of recovery (see Table 2). Service provider network (-0.114) had a very weak negative relationship with perceptions of recovery. This relationship was also not statistically significant therefore Hypothesis 1 was not supported. Service provider network was also not significantly correlated with any of the perceptions of recovery subscales. However, both social support and family relations were significantly and positively correlated to perceptions of recovery and all of its subscales. Social support (0.408) indicated a moderate relationship with perceptions of recovery 
whereas family relations $(0.281)$ had a weak relationship with perceptions of recovery. Hypotheses 2 and 3 were supported.

Service provider network was not significantly correlated with either social support or family relations. However, social support and family relations had a weak positive and significant correlation with each other (0.284). Social support had the highest significant association with the perceptions of recovery subscale 'reliance on others' $(0.453)$ and the weakest significant association to the 'goal and success orientation' subscale (0.185). Family relations indicated the strongest significant correlation with overall perceptions of recovery (0.281) and the weakest significant association with the 'goal and success orientation' subscale (0.155).

Figure 2. Hierarchical regression results for final model.

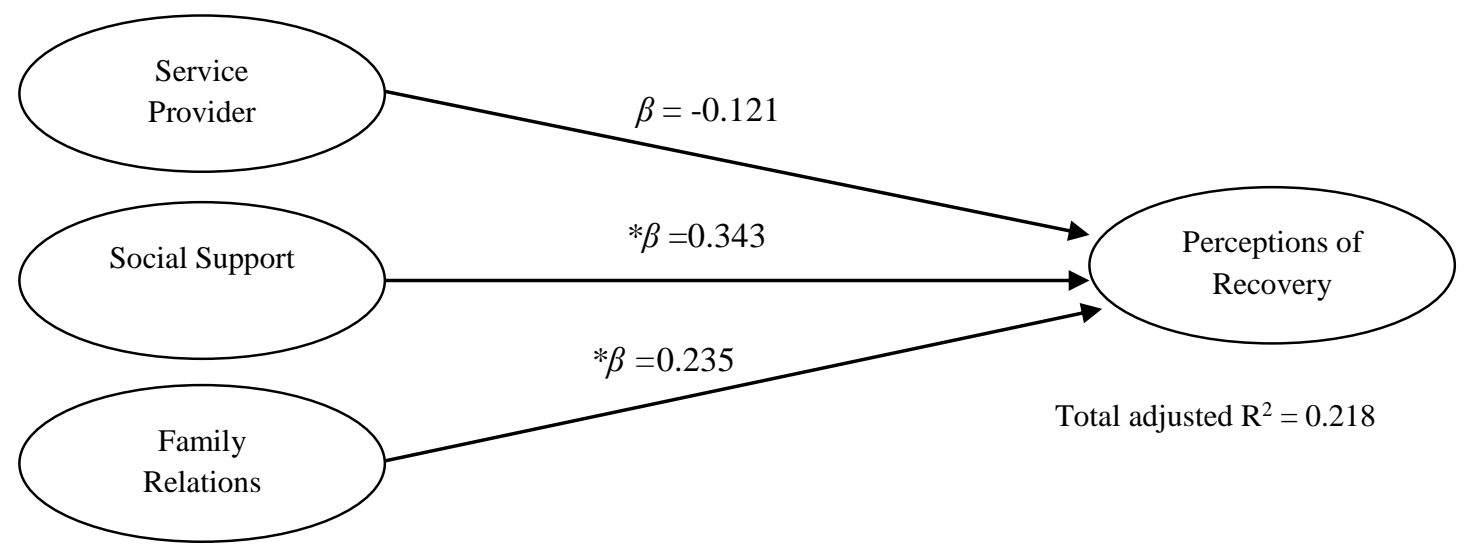

*All values significant at $\mathrm{p}<0.01$.

\section{Multiple Regression Analysis}

Hierarchical multiple regression was used to test Hypothesis 4. Because of a statistically significant difference in the means of both groups, sex was initially included in the regression model. The model was analysed with and without the sex variable. It did not influence the total variance that the model explained in perceptions of recovery therefore, in keeping the model as 
Table 2: Means, Standard Deviations, Reliability and Correlations among study variables

\begin{tabular}{|c|c|c|c|c|c|c|c|c|c|c|c|c|c|}
\hline & Variable & Range & Mean $(S D)$ & $\mathrm{a} \dagger^{\dagger}$ & 1 & 2 & 3 & 4 & 5 & 6 & 7 & 8 & 9 \\
\hline 1 & $\begin{array}{l}\text { Service Provider } \\
\text { Network }\end{array}$ & $0-10$ & $0.97(1.026)$ & - & - & & & & & & & & \\
\hline 2 & Social Support & $1-7$ & $4.91(1.143)$ & .767 & .718 & - & & & & & & & \\
\hline 3 & Family Relations & $1-7$ & $3.80(1.505)$ & .841 & .142 & $.284 *$ & - & & & & & & \\
\hline 4 & $\begin{array}{l}\text { Perceptions of } \\
\text { Recovery }\end{array}$ & $1-5$ & $\begin{array}{l}3.72 \\
(0.575)\end{array}$ & .881 & -.114 & $.408 *$ & $.281 *$ & - & & & & & \\
\hline 5 & $\begin{array}{l}\text { Personal } \\
\text { Confidence } \\
\text { and Hope }\end{array}$ & $1-5$ & $3.84(0.670)$ & .763 & -.128 & $.329 *$ & $.242 *$ & $.870^{*}$ & - & & & & \\
\hline 6 & $\begin{array}{l}\text { Willingness to } \\
\text { ask for Help }\end{array}$ & $1-5$ & $3.59(0.927)$ & .808 & .000 & $.233 *$ & $.177 *$ & $.640^{*}$ & $.387 *$ & - & & & \\
\hline 7 & $\begin{array}{l}\text { Goal and } \\
\text { Success } \\
\text { Orientation }\end{array}$ & $1-5$ & $4.05(0.685)$ & .768 & -.107 & $.185^{*}$ & $.155^{*}$ & $.774^{*}$ & $.686^{*}$ & $.359 *$ & - & & \\
\hline 8 & $\begin{array}{l}\text { Reliance on } \\
\text { Others }\end{array}$ & $1-5$ & $3.83(0.794)$ & .729 & .058 & $.453 *$ & $.276^{*}$ & $.631 *$ & $.424 *$ & $.394 *$ & $.304 *$ & - & \\
\hline 9 & $\begin{array}{l}\text { Not Dominated } \\
\text { by Symptoms }\end{array}$ & $1-5$ & $3.08(1.00)$ & .769 & -.104 & $.223 *$ & $.221 *$ & $.591 *$ & $.415^{*}$ & $.225 *$ & $.261 *$ & $.242 *$ & - \\
\hline
\end{tabular}

Note: *All correlations statistically significant at $\mathrm{p}<0.01$.

$\dagger$ Cronbach's alpha. 
parsimonious as possible, sex was not included in the final model.

The central tenet in Peplau's theory of Interpersonal Relations is interpersonal processes between service providers and clients (Peplau, 1991). Peplau (1991) suggests that the relationship between a service provider is an influential factor in the client's outcome (Forchuk, 1991). Thus, service provider network was entered into the regression model first, followed by social support in the second step, and then followed by family relations in the third step with perceptions of recovery as the dependent variable (see Table 3 ).

Table 3: Hierarchical regression results for all models

\begin{tabular}{|c|c|c|c|c|c|c|}
\hline Models & $B(S E)$ & $\beta$ & $\Delta R^{2}$ & $R^{2}$ & t-statistic & Sig. \\
\hline $\begin{array}{l}\text { Service Provider } \\
\text { Network }\end{array}$ & $-1.387(0.976)$ & -0.124 & 0.015 & 0.015 & -1.42 & 0.158 \\
\hline $\begin{array}{l}\text { Service Provider } \\
\text { Network }\end{array}$ & $-0.923(0.907)$ & -0.082 & & & & 0.311 \\
\hline $\begin{array}{l}\text { Social } \\
\text { Support }\end{array}$ & $4.579(0.950)$ & 0.390 & 0.150 & 0.166 & $4.82 *$ & 0.000 \\
\hline $\begin{array}{l}\text { Service Provider } \\
\text { Network }\end{array}$ & $-1.358(0.894)$ & -0.121 & & & -1.52 & 0.132 \\
\hline $\begin{array}{l}\text { Social } \\
\text { Support }\end{array}$ & $4.032(0.942)$ & 0.343 & & & $4.28^{*}$ & 0.000 \\
\hline $\begin{array}{l}\text { Family } \\
\quad \text { Relations }\end{array}$ & $1.983(0.680)$ & 0.235 & 0.052 & 0.218 & $2.92 *$ & 0.004 \\
\hline
\end{tabular}

Outcome: Perceptions of Recovery. B, unstandardised beta; SE, standardised error; $\beta$ standardised beta; $\Delta R^{2}$, delta $R$-squared.

*All values statistically significant at $p<0.01$.

In the final model, service provider network accounted for $1.5 \%$ of the variance in perceptions of recovery $\left(\mathrm{R}^{2}=0.015\right)$ and was not a significant predictor $(\beta=-0.124, t=-1.42$, $p=0.158$ ) of perceptions of recovery. The addition of social support explained a further $15.1 \%$ of the variance $\left(\mathrm{R}^{2}=0.166\right)$ and was a significant predictor of perceptions of recovery $(\beta=0.390$, $t=4.82, p=<0.00)$. Family relations explained another $5.2 \%\left(\mathrm{R}^{2}=0.218\right)$ and was also a significant predictor of perceptions of recovery $(\beta=0.390, t=4.82, p=<0.00)$. A total of $21.8 \%$ of 
the variance in perceptions of recovery was explained by all three variables. Thus, Hypothesis 4 was partially supported since social support and family relations were the only significant predictors of perceptions of recovery. See Table 3 for details of the model and Figure 2 for the final model.

\section{Discussion}

The findings from this study support Peplau's theory $(1991,1992,1997)$ that interpersonal relations play an important role in influencing perceptions of recovery. The purpose of this study was to examine the relationship between service provider network, social support, family relations, and perceptions of recovery in a sample of homeless youth. More specifically, it was hypothesized that a larger network of service providers and higher levels of perceived social support and family relations would result in an increase in homeless youth's perceptions of recovery. Partial support was found for this hypothesis because social support and family relations were the only variables significantly, positively associated with perceptions of recovery. Network of service providers was not a significant predictor of perceptions of recovery. The overall model combining service provider network, social support, and family relations explained $21.8 \%$ of the variance in perceptions of recovery.

Peplau's (1997) theory of Interpersonal Relations states that relationships with service providers are important in the process of achieving a higher level of health. Other studies have reinforced Peplau's theory, stating that service providers are extremely influential and crucial to the recovery process of homeless youth (Bartle-Haring, 2012; Krabbenborg et al., 2013; McCay et al., 2011). Despite findings from the literature, the service provider network variable used in this study was not a significant predictor of perceptions of recovery. This may be attributed to multiple factors including that the network of service providers variable was a derived variable. In addition, very few participants reported contact with a service provider limiting the ability to 
assess the impact of a network of service providers on perceptions of recovery. Perhaps, as opposed to examining the number of service providers, a better representation of the influence of service providers would be the services rendered by the homeless youth, or the strength of the relationship between the service provider and the youth.

Many study participants reported no relationship with a service provider of any sort $(M=0.97, S D=1.026)$. Among the sample of 184 homeless youth in this study, 73 participants reported having made no contact with any service provider. The majority of participants that reported relationships with service providers did not have a network extending beyond two providers. In this study, only 14 homeless youth reported contact with three or more providers. Findings from the literature regarding the patterns of service use among homeless youth are not well understood (Hughes et al., 2010). There is ample evidence that homeless youth do not actively seek support and assistance with their problems until the symptoms become unmanageable in their life (Reutter, Hungler, Letourneau, Makwarimba, \& Stewart, 2010; Soloria, Milburn, Andersen, Trifskin, \& Rodriguez, 2006). Some studies suggest that homeless youth have a tendency to use coping styles that distance them from stressors (Canadian Institutes for Health Information, 2007; Schmitz, Wagner, \& Menke, 2001). However, there is some evidence that they seldom use services when they are free (Miller, Donahue, Esta, \& Hofer, 2004; Hughes et al., 2010). Despite these inconsistencies, the literature consistently states that homeless youth with mental health problems are even less likely to receive treatment (Soloria et al., 2006; Moses, 2009). Therefore, it is not unexpected that the network of service providers that the participants accessed was either absent or extremely minimal. This finding indicates that service utilization among the homeless youth population is an issue and interventions must be created to improve access and utilization of services. 
Of all three predictor variables in the model, social support $(\beta=0.343)$ had the strongest influence on perceptions of recovery. Social supports constitute an individual's network of supportive relationships (Peplau, 1997). Supportive relationships confirm self-confidence and self-esteem, concepts heavily related to perceptions of recovery (Peplau, 1992; Stewart et al., 2009). Participants in the study were not neutral about the time spent with other people socially. They reported slight happiness with the social support present in their lives $(M=4.91, S D=1.143)$.

Family relations was also a significant predictor of youth's perceptions of recovery. Family relations have been identified in the literature as being crucial during periods of transition and in building resiliency in youth (Windland et al., 2011; Werner \& Smith, 1992). Although still positive, the homeless youth in this study reported lower scores in their feelings about their contact and interactions with family members $(M=3.80, S D=1.505)$ than with social support. These findings are consistent with the literature stating that many homeless youth have strained relationships with some of their family members despite the emotional and caring support they receive from other members during critical life situations (Kurtz et al., 2000; Hughes et al., 2010; Nebbitt et al., 2007). The addition of family relations $(\beta=0.235)$ in the model explained more variance in the youth's perception of recovery (adjusted $R^{2}=0.218$ ) than social support on its own (adjusted $\left.R^{2}=0.166\right)$.

Peplau's theory, grounded in the belief that individuals heal in supportive relationships is validated from this study (Forchuk et al., 2007; Peplau, 1997). These findings are also consistent with the literature stating that social support and family relations are crucial throughout a homeless youth's recovery process (Hughes et al., 2010; Kurtz et al., 2000; Stewart et al., 2009; Kidd \& Shahar, 2008). Given the influence of these interpersonal relationships, securing these supports may be beneficial throughout all intervention programs. Connecting homeless youth 
with other individuals their age, undergoing the same challenges may help to create bonds and supportive relationships. Further, the influence of specific family relations on the recovery process should not be overlooked among interventions. Family relations must be assessed to identify if, when, and which family members can be integrated and supportive throughout the intervention process. A more family-centered approach, incorporating family counseling to reconnect specific members and improve relationships may assist in overcoming obstacles faced in the past (Windland et al., 2011). Integral to the success of peer and familial relationships is assessing the influence of these relationships on the homeless youth. As identified in the literature, positive relationships with peers and family can improve self-esteem, resiliency, hope, confidence, mentorship, and motivation however unsupportive relationships can perpetuate the cycle of poor health, substance use, and poor QoL (Rew et al., 2001; Rice, Milburn, \& Monro, 2011; Adams \& Berzonsky, 2005; Karabanow \& Clement, 2004; Hughes et al., 2010).

Perceptions of recovery is a concept with multiple dimensions. The key to creating effective interventions is to understand how the youth perceives the dimensions of recovery. In this study, on average, the participants reported the highest scores to the RAS subscale, goal and success orientation $(M=4.05, S D=0.685)$ indicating that they have a desire to succeed and believe they have a purpose in life. This sense of purpose and ability to succeed may arise from the motivation and esteem received from the supportive relationships indicated in this study. These findings are also consistent with other intervention programs with the homeless youth whereby the youth voluntarily sought out treatment (Walker, 2008; Julianelle, 2007; Cleverley \& Kidd, 2011).

The participants, on average, also reported high scores on the RAS subscale, reliance on others $(M=3.83, S D=0.794)$. In line with Peplau's $(1991,1997)$ theory of Interpersonal 
Relations, reliable supports that the youth feel believe in them when their personal esteem is low are important in their perception of recovery. Similarly, the personal confidence and hope $(M=3.84, S D=0.670)$ also had high scores. Hope, seen as a maintaining factor and trigger in the process of recovery has been identified in the literature as a crucial component in an youth's ability to recover (Kirst et al., 2014; Padgett, Henwood, Abrams, \& Drake, 2008; Padgett \& Henwood, 2011, 2012; Henwood et al., 2013; Hughes et al., 2010). Personal confidence has been associated with one's ability to define purpose and meaning in their life (Jacobson \& Greenley, 2001; Mancini, 2008; Resnick et al., 2005; Helseth \& Misvaer, 2010). Therefore, it is logical that goal and success orientation and personal confidence and hope subscales had similarly high scores among the sample of participants. This study supports the concepts found in the literature as being central to the process of recovery. It also reinforces the importance of intrapersonal skills (hope, confidence, finding purpose, resilience) and highlights the necessity of supportive relationships that encourage the development and application of such skills.

Willingness to ask for help $(M=3.59, S D=0.927)$, a subscale on the RAS, although still at the positive end the scale, received lower scores. This suggests that, on average, the participants struggled more with knowing when to ask for help and their willingness to ask for help even when they believed they needed it. This result is not unexpected as many of the homeless youth in this study had no relationships, or very few relationships, with service providers. Although a causal link cannot be made between willingness to seek help and the size of their service provider network as this extends beyond the scope of this paper, the relative uncertainty expressed by the participants is consistent with the literature that homeless youth do not always seek support (Reutter et al., 2010). The literature has identified that this results from embarrassment, concerns about the services, negative perceptions of providers, not knowing 
where or how to ask for help, and feelings of judgement (Hudson et al., 2010; Kozloff et al., 2013).

Participants reported the lowest scores for the 'not dominated by symptoms' subscale $(M=3.08 ; S D=1.00)$ on the RAS. This suggests that, on average, the participants struggled most with their ability to effectively cope with their mental illness and the interference of its symptoms on their everyday life. Participants were uncertain of the pervasiveness of their mental illness and their ability to manage their symptoms. These findings are consistent with the literature as the majority of homeless youth do not have a formal mental diagnosis (Eva's Initiatives, 2012a). Therefore, these youth are unable to manage, cope, and acknowledge the symptoms they are experiencing (Kidd, 2013; Eva's Initiatives, 2012).

Recovery is a multifaceted process that incorporates many approaches. This study affirmed the importance of social support and family relations in the recovery process of homeless youth however this model accounted for only $21.8 \%$ of the variance in perceptions of recovery. Therefore, there are other factors that contribute to the recovery of homeless youth and must be considered when designing and implementing interventions. Housing has been identified as an integral factor that can facilitate and support dimensions of recovery (Kirst et al., 2014; Tsemberis, Gulcur, \& Nakae, 2004; Forchuk et al., 2013; Tsemberis, Kent, \& Respress, 2012). Housing has been seen by homeless youth as a preliminary step in rebuilding their lives (Kirst et al., 2014). Substance use treatment and mental health programs are also important in the recovery of homeless youth as it assists them in exiting a cycle that leads many back into homelessness (Tsemberis et al., 2004; Forchuk et al., 2013). Employment also facilitates the process of recovery by providing youth with hope, skills, income, and a safe and sustainable way to stay off the streets (Gaetz \& O’Grady, 2013). Education is an approach that teaches homeless 
youth the skills and knowledge necessary for employment (Gaetz \& O’Grady, 2013; Liljedahl, Rae, Aubry, \& Klodawsky, 2013). Education, a goal of many homeless youth, also enables hope and improves self-confidence and esteem. Adequate food and nutrition are necessary to rebuild healthy habits necessary to maintaining well-being throughout the lifespan (Dachner \& Tarasuk, 2013). It is evident that the process of recovery for homeless youth is not a single dimensioned approach. It involves multiple approaches that meet all aspects of the youth's life.

\section{Limitations}

There are some limitations in this study which should be considered. The potential of response bias as a result of using self-report questionnaires must be considered. Due to the sensitivity of some questions in the study, youth may have been hesitant to share certain feelings or behaviours, although confidentiality was emphasized. In an effort to reduce this type of bias, research assistants spent many hours at the drop-in centres interacting with the youth to build trust. A trusted peer of similar age conducting the interview may allow for more honesty and openness in the youth's responses and increased comfort. As a whole, self-report measures are cost effective and more time efficient than other methods, however the methodology has potential for bias (Polit \& Beck, 2008). The cross-sectional nature of the analysis poses as a limitation in its ability to support strong causal claims due to the fact that information was gathered at one point in time (Polit \& Beck, 2008). The majority of study participants were of similar age and therefore findings may not represent homeless youth at different developmental stages. Furthermore, the study population was a convenience sample, obtained from drop-in centres and shelter services in one city. As a result, homeless youth who do not access such services are not included in this analysis and the results may not be applicable to them. However, the demographic data is consistent with other studies of homeless youth in various cities across Canada. 
The derived variable of Service Provider network may not have accurately captured the impact of the relationships between the service providers and the youth. This in turn may not have accurately portrayed the correlation between a homeless youth's perceptions of recovery and size of service provider network. Additionally, the low number of participants who had seen a service provider limited the ability to test the impact of service provider network on youth perceptions of recovery. Finally, as with all secondary analyses, the measures used to examine the variables in this study was limited by the measures used in the original primary study. More directed questions examining the quality of relationships with service providers may be useful in future studies to evaluate its impact on perceptions of recovery.

\section{Conclusion}

The results of this study provide support for Peplau's $(1991,1992)$ theory of Interpersonal Relations and the correlations between service provider network, social supports, family relations, and perceptions of recovery. The combination of service provider network, social supports, and family relations explained $21.8 \%$ of the variance in homeless youth's perceptions of recovery. Although service provider network was not significantly correlated with perceptions of recovery, both social support and family relations were significantly and positively correlated. The results reinforce the importance of creating a supportive network for homeless youth throughout recovery. All supportive individuals in the lives of homeless youth encourage the development of different skills that are critical in obtaining a higher level of health. It is essential that health and social service organizations working with this demographic not only implement but promote policies and approaches that create supportive environments and relationships. Supportive relationships foster the growth and development necessary for homeless youth to recover from homelessness. 
References

Adams, G. R., \& Berzonsky, M. D. (2005). Blackwell handbook of adolescence. Hoboken, NJ: Wiley- Blackwell.

Abbott, P. (2008). Another step towards understanding recovery? Invited commentary on selfdetermination theory. Advances in Psychiatric Treatment, 14(5), 366-368.

Anthony, W. A. (1993). Recovery from mental illness: The guiding vision of the mental health service system in the 1990s. Psychosocial Rehabilitation Journal, 16(4), 11-23.

Bantchevska, D., Erdem, G., Patton, R., Linley, J., Letcher, A., Bonomi, A., \& Slesnick, N. (2011). Predictors of drop-in center attendance among substance-abusing homeless adolescents. Social Work Research, 35(1), 58-63.

Barbic, S., Krupa, T., \& Armstrong, I. (2009). A randomized controlled trial of the effectiveness of a modified recovery workbook program: Preliminary findings. Psychiatric Services, 60(4), 491-497.

Bartle-Haring, S. (2012). The utility of mentoring homeless adolescents: A pilot study. The American Journal of Drug and Alcohol Abuse, 38(4), 350-358.

Bao, W.N., Whitbeck, L.B., \& Hoyt, D.R. (2000). Abuse, support, and depression among homeless and runaway youth. Journal of Health and Social Behavior, 41(4), 408-420.

Bearsley, C., \& Cummins, R. A. (1999). No place called home: Life quality and purpose of homeless youths. Journal of Social Distress \& the Homeless, 8, 207-226.

Bhui, K., Shanahan, L., \& Harding, G. (2006). Homelessness and mental illness: A Literature review and a qualitative study of perceptions of the adequacy of care. International Journal of Social Psychiatry, 52(2), 152-165.

Canadian Institutes for Health Information. (2007). Improving Health of Canadians 2007-2008: Mental health and homelessness. Ottawa, Canada: Author.

Carlson, J. L., Sugano, E., Millstein, S. G., \& Auerswald, C. L. (2006). Service utilization and the life cycle of youth homelessness. Journal of Adolescent Health, 38(5), 624-627.

Cheng, T., Wood, E., Nguyen, P., Kerr, T., \& DeBeck, K. (2014). Increases and decreases in drug use attributed to housing status among street-involved youth in a Canadian setting. Harm Reduction Journal, 11(1), 1 - 6.

Cheung, A. M., \& Hwang, S. W. (2004). Risk of death among homeless women: A cohort study and review of the literature. Canadian Medical Association Journal, 170(8), 1243-1247.

Cleverley, K., \& Kidd, S.A. (2011). Resilience and suicidality among homeless youth. Journal of Adolescence, 34(5), 1049-1054. 
Cohen, J. (1988). Statistical power analysis for the behavioral sciences ( $3^{\text {rd }}$ ed.). Hillsdale, NJ: Laurence-Erlbaum.

Cohen, S. (2003). Psychosocial models of the role of social support in the etiology of physical disease. In P. Salovey \& A.J. Rothman (Eds.) Social psychology of health (227-44). New York: Psychology Press.

Corrigan, P. W., Giffort, D., Rashid, F., Leary, M., \& Okeke, I. (1999). Recovery as a psychological construct. Community Mental Health Journal, 35(3), 231-239.

Corrigan, P. W., Salzer, M., Ralph, R. O., Sangster, Y., \& Keck, L. (2004). Examining the factor structure of the recovery assessment scale. Schizophrenia Bulletin, 30(4), 1035-1041.

Cummins, R. A. (1995). On the trail of the gold standard for subjective well-being. Social Indicators Research, 35, 179-200.

Currie, C., \& LaBoucane-Benson, P. (2011). Impacts of a peer support program for streetinvolved youth. Journal of Aboriginal and Indigenous Community Health, 9(1), 177-191.

Dachner, N., \& Tarasuk, V. (2013). Homeless youth, nutritional vulnerability, and community food assistance program. In S. Gaetz, B. O'Grady, K. Buccieri, J. Karabanow, \& A. Marsolais (Eds.). Youth homelessness in Canada: Implications for policy and practice (pp. 131-146). Toronto, Ontario: Canadian Homelessness Research Network

Dadds, M.R., Braddock, D., Cuers, S., Elliott, A., \& Kelly, A. (1993). Personal and family distress in homeless adolescents. Community Mental Health Journal, 29, 413-422.

Davidson, L., \& White, W. (2007). The concept of recovery as an organizing principle for integrating mental health and addiction services. The Journal of Behavioral Health Services \& Research, 34(2), 109-120.

Deegan, P. E. (1988). Recovery: The lived experience of rehabilitation. Psychosocial Rehabilitation Journal, 11, 11-19.

Deegan, P.E. (1996). Recovery as a journey of the heart. Psychiatric Rehabilitation Journal, 19, 91-97.

Essock, S., \& Sederer, L. (2009). Understanding and measuring recovery. Schizophrenia Bulletin, 35(2), 279-281.

Eva's Initiatives. (2012a). Backgrounder on Homeless Youth and Mental Health. Retrieved from http://www.evasinitiatives.com/2012/05/07/backgrounder-on-homeless-youth-andmental-health/

Eva's Initiatives. (2012). National Snapshot on Mental Health Issues for Homeless Youth. Retrieved from http://evasinitiatives.com/2012/05/07/evas-releases-national-snapshot-onmental-healthissues-in-homeless-youth/ 
Evans, S., \& Huxley, P. (2002). Studies of quality of life in the general population. International Review of Psychiatry, 14, 203-211.

Evanson, J. (2009). Youth homelessness in Canada: The road to solutions. Raising the Roof. Retrieved from http://www.raisingtheroof.org/

Faul, F., Erdfelder, E., Buchner, A., \& Lang, A.G. (2009). Statistical power analyses using $\mathrm{G}^{*}$ Power 3.1: Tests for correlation and regression analyses. Behaviour Research Methods, 41, 1149-1160.

Feng, C., DeBeck, K., Kerr, T., Mathias, S., Montaner, J., \& Wood, E. (2013). Homelessness independently predicts injection drug use initiation among street-involved youth in a Canadian setting. The Journal of Adolescent Health, 52(4), 499-501.

Forchuk, C., \& Brown, B. (1989). Establishing a nurse-client relationship. Journal of Psychosocial Nursing, 27(2), 30-34.

Forchuk, C. (1991). Peplau's theory: Concepts and their relations. Nursing Science Quarterly, 4(2), 54-60.

Forchuk, C., Jewell, J., Schofield, R., Sircelj, M., \& Valledor, T. (1998). From hospital to community: Bridging therapeutic relationships. Journal of Psychiatric and Mental Health Nursing, 5(3), 197-202.

Forchuk, C., Reynolds, W., Sharkey, S., Martin, M., \& Jensen, E. (2007). Transitional discharge based on therapeutic relationships: State of the art. Archives of Psychiatric Nursing, 21(2), 80-86.

Forchuk, C., Richardson, J., Laverty, K., Bryant, M., Csiernik, R., Edwards, B., ... \& Kelly, C. (2013). Service preferences of homeless youth with mental Illness: Housing first, treatment first, or both together. In S. Gaetz, B. O’Grady, K. Buccieri, J. Karabanow, \& A. Marsolais (Eds.). Youth homelessness in Canada: Implications for policy and practice, 95-110. Toronto, Ontario: Canadian Homelessness Research Network

Gaetz, S. (2004). Safe streets for whom? Homeless youth, social exclusion, and criminal victimization. Canadian Journal of Criminology and Criminal Justice, 46, 423-456.

Gaetz, S., \& O’Grady, B. (2013). Why Don't You Just Get a Job? Homeless Youth, Social Exclusion and Employment Training. In S. Gaetz, B. O’Grady, K. Buccieri, J. Karabanow, \& A. Marsolais (Eds.) Youth homelessness in Canada: Implications for policy and practice (pp. 243-268). Toronto, Ontario: Canadian Homelessness Research Network

Giffort, D., Schmook, A., Woody, C., Vollendorf, C., \& Gervain, M. (1995). Construction of a scale to measure consumer recovery. Springfield, IL: Illinois Office of Mental Health. 
Grossman, J. B., \& Rhodes, J. E. (2002). The test of time: Predictors and effects of duration in youth mentoring relationships. American Journal of Community Psychology, 30, 199219.

Harvey, P. D., \& Bellack, A. S. (2009). Toward a terminology for functional recovery in schizophrenia: Is functional remission a viable concept? Schizophrenia Bulletin, 35(2), 300-306.

Helseth, S., \& Misvaer, N. (2010). Adolescents' perceptions of quality of life: What it is and what matters. Journal of Clinical Nursing, 19(9-10), 1454-1461.

Henwood, B. F., Hsu, H. T., Dent, D., Winetrobe, H., Carranza, A., \& Wenzel, S. (2013). Transitioning from homelessness: A "Fresh-Start" event. Journal of the Society for Social Work and Research, 4(1), 47-57.

Hogan, B.E. (2002). Social support interventions: Do they work?. Clinical Psychology Review, $22,381-440$.

Hogan, M. F. (2003). New freedom commission report: The president's new freedom commission: Recommendations to transform mental health care in America. Psychiatric Services, 54(11), 1467-1474.

Holloway, F. (2008). Is there a science of recovery and does it matter?: Invited commentary on recovery and the medical model. Advances in Psychiatric Treatment, 14(4), 245-247.

Hubley, A. M., Russell, L. B., Palepu, A., \& Hwang, S. W. (2014). Subjective quality of life among individuals who are homeless: A review of current knowledge. Social Indicators Research, 115(1), 509-524.

Hudson, A. L., Nyamathi, A., Greengold, B., Slagle, A., Koniak-Griffin, D., Khalilifard, F., \& Getzoff, D. (2010). Health-seeking challenges among homeless youth. Nursing Research, 59(3), 212-218.

Hughes, J. R., Clark, S. E., Wood, W., Cakmak, S., Cox, A., Macinnis, M., . . Broom, B. (2010). Youth homelessness: The relationships among mental health, hope, and service satisfaction. Journal of the Canadian Academy of Child and Adolescent Psychiatry, 19(4), 274-283.

Hwang, S. (2000). Mortality among men using homeless shelters in Toronto, Ontario. Journal of American Medical Association, 283(16), 2152-2157

Hwang, S. W. (2001). Homelessness and health. Canadian Medical Association Journal, 164(2), 229-233. 
Hwang, S. W., Ueng, J. J. M., Chiu, S., Kiss, A., Tolomiczenko, G., Cowan, L., . . Redelmeier, D. A. (2010). Universal health insurance and health care access for homeless persons. American Journal of Public Health, 100(8), 1454-1461.

IBM Corporation. (2013). IBM SPSS Statistics for Windows, Version 22.0. Armonk, NY: IBM Corp.

Jacobson, N., \& Greenley, D. (2001). What is recovery?. A conceptual model and explication. Psychiatric Services, 52(4), 482-485.

Johnson, T. P., Freels, S. A., Parsons, J. A., \& Vangeest, J. B. (1997). Substance abuse and homelessness: Social selection or social adaptation? Addiction, 92(4), 437-445.

Jones, W., Goldner, E., Butler, A., \& McEwan, K. (2014). Informing the future: Mental health indicators for Canada technical report. Retrieved from http://www.mentalhealthcommission.ca

Julianelle, P. (2007). The educational success of homeless youth in California: Challenges and solutions. Sacramento, CA: California Research Bureau

Karabanow, J., \& Clement, P. (2004). Interventions with street youth: A commentary on the practice-based research literature. Brief Treatment and Crisis Intervention, 4(1), 93-108.

Karabanow, J., \& Naylor, T. (2010). Being hooked-up: Exploring the experiences of street youth with information communication technology. In E. D. Looker \& T. D. Naylor (Eds.), Digital diversity: Youth, equity, and information technology (pp. 161-178). Waterloo: Wilfred Laurier Press.

Karabanow, J., Naylor, T. (2013). Pathways towards stability: Young people's transition off the streets. In S. Gaetz, B. O'Grady, K. Buccieri, J. Karabanow, \& A. Marsolais (Eds.), Youth Homelessness in Canada: Implications for Policy and Practice (pp. 39-52). Toronto: Canadian Homelessness Research Network Press Kertesz, S. G., Larson, M. J.,

Kellar, S. P., \& Kelvin, E. A. (2013). Munro's statistical methods for health care research. Philadelphia: Wolters Kluwer Health/Lippincott Williams \& Wilkins.

Kidd, S. A. (2003). Street youth: Coping and interventions. Child and Adolescent Social Work Journal, 20(4), 235-261.

Kidd, S. (2013). Mental health and youth homelessness: A critical review. In S. Gaetz, B. O’Grady, K. Buccieri, J. Karabanow, \& A. Marsolais (Eds.). Youth homelessness in Canada: Implications for policy and practice (pp. 217-227). Toronto, Ont: Canadian Homelessness Research Network.

Kidd, S., \& Shahar, G. (2008). Resilience in homeless youth: The key role of self-esteem. American Journal of Orthopsychiatry, 78(2), 163-172. 
Kirst, M., Zerger, S., Wise Harris, D., Plenert, E., \& Stergiopoulos, V. (2014). The promise of recovery: Narratives of hope among homeless individuals with mental illness participating in a housing first randomised controlled trial in Toronto, Canada. BMJ Open, 4(3), 1-8.

Kozloff, N., Cheung, A. H., Ross, L. E., Winer, H., Ierfino, D., Bullock, H., \& Bennett, K. J. (2013). Factors influencing service use among homeless youths with co-occurring disorders. Psychiatric Services, 64(9), 925-928.

Krabbenborg, M. A. M., Boersma, S. N., \& Wolf, J. R. L. M. (2013). A strengths based method for homeless youth: Effectiveness and fidelity of Houvast. BMC Public Health, 13(1), 359-359.

Kuhns, M. (2007). Theories from the behavioral sciences. In M. McEwen \& M. E. Wills (Eds.), Theoretical basis for nursing (2nd ed., pp.300-327). Philadelphia, PA: Lippincott, Williams \& Wilkins.

Kurtz, P. D., Lindsey, E. W., Jarvis, S., \& Nackerud, L. (2000). How runaway and homeless youth navigate troubled waters: The role of formal and informal helpers. Child and Adolescent Social Work Journal, 17(5), 381-402.

Lansdowne, J. (2011). The SMART fund: The links between social support and improved health outcomes. Vancouver Costal Health: Simon Fraser University

Larson, C. O. (2002). Use of the SF-12 instrument for measuring the health of homeless persons. Health Services Research, 37, 733-750.

Leete, E. (1989). How I perceive and manage my illness. Schizophrenia Bulletin, 15(2), 197-200.

Lehman, A.F., Ward, N. C., \& Linn, L.S. (1982). Chronic mental patients: The quality of life issue. The American Journal of Psychiatry, 10, 1271-1276.

Lehman, A.F., Possidente, S., \& Hawker, F. (1986). The quality of life of chronic mental patients in a state hospital and community residences. Hospital Community Psychiatry, 37, 901907.

Lehman, A. (1988) A quality of life interview for the chronically mentally ill. Evaluation and Program Planning, 11, 51-62

Lehman, A.F. (1996). Measures of quality of life among persons with severe and persistent mental disorders. Social Psychiatry and Psychiatric Epidemiology, 31, 78-88. 
Liljedahl, S., Rae, J., Aubry, T., \& Klodawsky, F. (2013). In S. Gaetz, B. O’Grady, K. Buccieri, J. Karabanow, \& A. Marsolais (Eds.). Youth homelessness in Canada: Implications for policy and practice (pp. 269-286). Toronto, On: Canadian Homelessness Research Network.

Lindsey, E. W., Kurtz, P. D., Jarvis, S., Williams, N. R., \& Nackerud, L. (2000). How runaway and homeless youth navigate troubled waters: Personal strengths and resources. Child and Adolescent Social Work Journal, 17(2), 115-140.

Mallett, S., Rosenthal. D., \& Keys, D. (2005). Young people, drug use, and family conflict: Pathways into homelessness. Journal of Adolescence, 28(2), 185-199.

Mancini, A. D. (2008). Self-determination theory: A framework for the recovery paradigm. Advances in Psychiatric Treatment, 14(5), 358-365.

Martijn, C., \& Sharpe, L. (2006). Pathways to youth homelessness. Social Science \& Medicine, 62(1), 1-12.

Martinez, T. E., Gleghorn, A., Marx, R., Clements, K., Boman, M., \& Katz, M. H. (1998). Psychosocial histories, social environment, and HIV risk behaviors of injection and noninjection drug using homeless youths. Journal of Psychoactive Drug, 30(1), 1-10.

Martins, D. C. (2008). Experiences of homeless people in the health care delivery system: A descriptive phenomenological study. Public Health Nursing, 25(5), 420-430.

McCay, E., Quesnel, S., Langley, J., Beanlands, H., Cooper, L., Blidner, R., . . Bach, K. (2011). A relationship-based intervention to improve social connectedness in street-involved youth: A pilot study. Journal of Child and Adolescent Psychiatric Nursing, 24(4), 208215.

McNaught, M., Caputi, P., Oades, L. G., \& Deane, F. P. (2007). Testing the validity of the recovery assessment scale using an Australian sample. Australasian Psychiatry, 41(5), 450-457.

Medlow, S., Klineberg, E., \& Steinbeck, K. (2014). The health diagnoses of homeless adolescents: A systematic review of the literature. Journal of Adolescence, 37(5), 531542.

Miller, P., Donahue, P., Este, D., \& Hofer, M. (2004). Experiences of being homeless or at risk of being homeless among Canadian youths. Adolescence, 39(156), 735-755.

Moran, G., Mashiach-Eizenberg, M., Roe, D., Berman, Y., Shalev, A., Kaplan, Z., Garber Epstein, P. (2014). Investigating the anatomy of the helping relationship in the context of psychiatric rehabilitation: The relation between working alliance, providers' recovery competencies and personal recovery. Psychiatry Research, 220(1-2), 592-597. 
Morrell-Bellai, T., Goering, P. N., \& Boydell, K. M. (2000). Becoming and remaining homeless: A qualitative investigation. Issues in Mental Health Nursing, 21, 581-604.

Moses, T. (2009). Stigma and self-concept among adolescents receiving mental health treatment. American Journal of Orthopsychiatry, 79(2), 261-274.

Mountain, D., \& Shah, P. J. (2008). Recovery and the medical model. Advances in Psychiatric Treatment, 14(4), 241-244.

Nebbitt, V. E., House, L. E., Thompson, S. J., \& Pollio, D. E. (2007). Successful transitions of runaway/homeless youth from shelter care. Journal of Child and Family Studies, 16(4), 545-555.

Nyamathi, A., Hudson, A., Greengold, B., Slagle, A., Marfisee, M., Khalilifard, F., \& Leake, B. (2010). Correlates of substance use severity among homeless youth. Journal of Child and Adolescent Psychiatric Nursing, 23(4), 214-222.

Padgett, D. K., Henwood, B., Abrams, C., \& Drake, R. E. (2008). Social relationships among persons who have experienced serious mental illness, substance abuse, and homelessness: Implications for recovery. American Journal of Orthopsychiatry, 78(3), 333-339.

Padgett, D. K., \& Henwood, B. F. (2012, 2011). Qualitative research for and in practice: Findings from studies with homeless adults who have serious mental illness and cooccurring substance abuse. Clinical Social Work Journal, 40(2), 187-193.

Palepu, A., Hubley, A. M., Russell, L. B., Gadermann, A. M., \& Chinni, M. (2012). Quality of life themes in Canadian adults and street youth who are homeless or hard-to-house: A multi-site focus group study. Health and quality of life outcomes, 10(1), 93.

Park, S., Kim, H. S., Kim, H., \& Sung, K. (2007). Exploration of the prevalence and correlates of substance use among sheltered adolescents in South Korea. Adolescence, 42, 603-616.

Peplau, H. E., (1952). Interpersonal relations in nursing: A conceptual frame of reference for psychodynamic nursing. New York: G. P. Putnam's Sons

Peplau, H. E. (1987). Interpersonal constructs for nursing practice. Nurse Education Today, 7 , 201-208.

Peplau, H. E. (1988). The art and science of nursing: Similarities, differences, and relations. Nursing Science Quarterly, 1(1), 8-15.

Peplau, H. E. (1991). Interpersonal relations in nursing: A conceptual frame of reference for psychodynamic nursing. New York: Springer Publishing Company.

Peplau, H.E. (1992). Interpersonal relations: A theoretical framework for application in nursing practice. Nursing Science Quarterly, 5(1), 13-18. 
Peplau, H. E. (1994). Quality of life: An interpersonal perspective. Nursing Science Quarterly, $7(1), 10-15$.

Peplau, H.E. (1997). Peplau's theory of interpersonal relations. Nursing Science Quarterly, 10(4), 162-167.

Pollio, D. E., Thompson, S. J., Tobias, L., Reid, D., \& Spitznagel, E. (2006). Longitudinal outcomes for youth receiving runaway/homeless shelter services. Journal of Youth and Adolescence, 35(5), 852-859.

Ralph, R.O. (2000). Review of recovery literature. Retrieved from http://www2.nami.org/Content/Microsites316/NAMI_PA,_Cumberland_and_Perry_Cos_ /Home310/Education27/ReviewOfRecovery_lit.pdf

Reid, S., Berman, H., \& Forchuck, C. (2005). Living on the streets in Canada: A feminist narrative study of girls and young women. Issues in Comprehensive Pediatric Nursing, 28, 237-256.

Resnick, S. G., Fontana, A., Lehman, A. F., \& Rosenheck, R. A. (2005). An empirical conceptualization of the recovery orientation. Schizophrenia Research, 75, 119-128.

Reutter, L., Hungler, K., Letourneau, N., Makwarimba, E., \& Stewart, M. (2010). Supporting homeless youth: Perspectives and preferences. Journal of Poverty, 14(2), 145-165.

Rew, L., Taylor-Seehafer, M., \& Fitzgerald, M. L. (2001). Sexual abuse, alcohol and other drug use, and suicidal behaviours in homeless adolescents. Issues in Comprehensive Pediatric Nursing, 24, 225-240.

Rice, E., Milburn, N. G., Rotheram-Borus, M., Mallet, S., \& Rosenthal, D. (2005). The effects of peer-group network properties on drug use among homeless youth. American Behavioral Scientist, 48, 1101-1123.

Riley, E. D., Bangsberg, D. R., Perry, S., Clark, R. A., Moss, A. R., \& Wu, A. W. (2003). Reliability and validity of the SF-36 in HIV-infected homeless and marginally housed individuals. An International Journal of Quality of Life Aspects of Treatment, Care \& Rehabilitation, 12, 1051-1058.

Rogers, E. S., Chamberlin, J., Ellison, M. L., \& Crean, T. (1997). A consumer-constructed scale to measure empowerment among users of mental health services. Psychiatric Services, 48(8), 1042-1047.

Rolf, J., Garmezy, N., Masten, A. S., Cicchetti, D., Nüchterlein, K. H., \& Weintraub, S. (1990). Risk and protective factors in the development of psychopathology. Cambridge, NY: Cambridge University Press. 
Schmitz, C. L., Wagner, J. D., \& Menke, E. (2001). The interconnection of childhood poverty and homelessness: Negative impact/points of access. Families in Society: The Journal of Contemporary Human Services, 82(1), 69-77.

Simpson, C.J., Hyde, C.E., \& Faragher, E.B. (1989). The chronically mentally ill in community facilities: A study of quality of life. The British Journal of Psychiatry, 154, 77-82.

Slesnick, N., Dashora, P., Letcher, A., Erdem, G., \& Serovich, J. (2009). A review of services and interventions for runaway and homeless youth: Moving forward. Children and Youth Services Review, 31(7), 732-742.

Smith, L. (2000). Protective factors and individual resilience. In Handbook of Early Childhood Intervention. Cambridge, NY: Cambridge University Press.

Soloria, M. R., Milburn, N. G., Andersen, R. M., Trifskin, S., \& Rodriguez, M. A. (2006). Emotional distress and mental health service use among urban homeless adolescents. Journal of Behavioral Health Services Research, 33(4), 381-393.

Spaniol, L., Wewiorski, N. J., Gagne, C., \& Anthony, W. A. (2002). The process of recovery from schizophrenia. International Review of Psychiatry, 14(4), 327-336.

Stewart, M., Reutter, L., Letourneau, N., \& Makwarimba, E. (2009). A support intervention to promote health and coping among homeless youths. Canadian Journal of Nursing Research, 41(2), 54-77.

Substance Abuse and Mental Health Services Administration. (2006). National census statement on mental health recovery. Rockville, MD: National Mental Health Information Center, US Government.

Substance Abuse and Mental Health Services Administration. (2014). Recovery and recovery Support. Retrieved from http://www.samhsa.gov/recovery

Sullivan, G., Burnam, A., Koegel, P., \& Hollenberg, J. (2000). Quality of life of homeless persons with mental illness: Results from the course-of-homelessness study. Psychiatric Services, 51(9), 1135-1141.

Sullivan, H. S. (1953). The interpersonal theory of psychiatry. New York: W. W. Norton \& Company, Inc.

Tsemberis, S., Gulcur, L., \& Nakae, M. (2004). Housing first, consumer choice, and harm reduction for homeless individuals with a dual diagnosis. American Journal of Public Health, 94(4), 651-656.

Tsemberis, S., Kent, D., \& Respress, C. (2012). Housing stability and recovery among chronically homeless persons with co-occurring disorders in Washington, DC. American Journal of Public Health, 102(1), 13-16. 
Uchino, B.N. (2004). Social support \& physical health: Understanding the health consequences of relationships. Connecticut: Yale University Press.

Unger, J.B., Kipke, M.D., Simon, T.R., Johnson, C.J., Montgomery, S.B., \& Iverson, E. (1998). Stress, coping, and social support among homeless youth. Journal of Adolescent Research, 13(2), 134-157.

Unzicker, R. (1989). On my own: A personal journey through madness and re-emergence. Psychosocial Rehabilitation Journal, 13(1), 71-77.

Uttaro, T., \& Lehman, A. (1999). Graded response modeling of the quality of life interview. Evaluation and Program Planning, 22(1), 41-52.

Walker, L. (2008). Waikiki youth circles: Homeless youth learn goal setting skills. Journal of Family Psychotherapy, 19(1), 85-96.

Werner, E. E., \& Smith, R. S. (1992). Overcoming the odds: High risk children from birth to adulthood. Ithaca: Cornell University Press.

Williams, P., Barclay, L., \& Schmied, V. (2004). Defining social support in context: A necessary step in improving research, intervention, and practice. Qualitative Health Research, 14(7), 942-960.

Winland, D. (2013). Reconnecting with Family and Community: Pathways Out of Youth Homelessness. In S. Gaetz, B. O’Grady, K. Buccieri, J. Karabanow, \& A. Marsolais (Eds.), Youth Homelessness in Canada: Implications for Policy and Practice (pp. 15-38). Toronto: Canadian Homelessness Research Network Press.

Winland, D., Gaetz, S., \& Patton, T. (2011). Family matters: Homeless youth and Eva's initiatives "family reconnect" program. Toronto: The Canadian Homelessness Research Network Press.

Young, S. L., \& Ensing, D. S. (1999). Exploring recovery from the perspective of people with psychiatric disabilities. Psychiatric Rehabilitation Journal, 22(3), 219-231.

Zuvekas, S. H., \& Hill, S.C. (2000). Income and employment among homeless people: The role of mental health, health and substance abuse. The Journal of Mental Health Policy and Economics, 3(3), 153-163. 


\section{Chapter Three}

The purpose of this study was to test Peplau's Theory of Interpersonal Relations (1991, 1992, 1997) by examining the relationships among service provider network, social support, family relations, and perceptions of recovery in a sample of homeless youth in the London, Middlesex region of Ontario. More specifically, it was hypothesized that a larger network of service providers and higher levels of perceived social support and family relations would result in an increase in homeless youth's perceptions of recovery. Partial support was found for this hypothesis as only social support and family relations were significantly associated with perceptions of recovery. Service provider network was not significantly related to perceptions of recovery. The combination of service provider network, social support, and family relations explained $21.8 \%$ of the variance in perceptions of recovery. The results of this study suggest that Peplau's (1992) Theory can be used as a framework to design and implement interventions for homeless youth that promote health and recovery.

\section{Implications for Nursing Practice}

The results of this study support Peplau's (1997) Theory that individuals heal in supportive environments and interpersonal relationships are necessary to support individuals through the process of recovery. Although the network of service providers was not significant in the proposed model, few of the participants actually had such relationships. This indicates that homeless youth faced limited access to professional support and services either as a result of having no services in the area to access, not knowing about services in the area, or choosing not to access services. Therefore, it is evident that intervention approaches are needed that improve access and provide opportunities for relationships between service providers and homeless youth to form. First, services must be accessible for youth regardless of their location or needs. Second, services must ensure that they are reaching the homeless youth population and that homeless 
youth are aware of supports that are available. Fostering awareness could be achieved through service providers visiting shelters or areas populated by homeless youth to educate them on supports available and where to access them. Hanging posters in shelters and areas populated by homeless youth may also increase awareness.

Throughout the literature, the quality of relationships between service providers and homeless youth has been identified as an important component in service utilization (Heinze et al., 2010; Dawson \& Jackson, 2013). The dimension of nursing in Peplau's (1952) Theory is achieved through the nurse-client relationship, and specific to the interpersonal relationship that develops between the nurse and the client. Nurses should be encouraged to implement Peplau's Theory (1952), including consistency and clarity in the roles of both members, and trust and open communication when interacting with clients (Forchuk, 1991). To foster consistency in relationships, it may be beneficial to have homeless youth assigned to a particular service provider or ensure all providers are educated on the same methods of interaction and care processes. Providing services that the youth perceive as helpful and rehabilitative may encourage utilization (Dawson \& Jackson, 2013).

In this study, the average (mean) scores of the dimensions of recovery were to the positive end of the scale. This indicates that, on average, the sample of homeless youth in this study had a desire to succeed and believed they had a purpose in life. They reported having hope, self-confidence and people who believed in them when they did not believe in themselves. These are all strengths that can be utilized throughout the process of recovery. Therefore it is important for the nurse or care provider to assess, harness and integrate the youth's strengths to facilitate recovery.

It is crucial that the nurse assess the extent of social and familial support in the lives of 
the homeless youth. The needs of homeless youth may differ depending on the extent of social and familial relationships present in their lives. Depending on the extent of supportive relationships in the youth's life, intervention and treatment plans may differ. The nurse must be aware of current supports to either encourage and strengthen healthy relationships or provide positive relationships for youth with none. Nurses may provide positive relationships through access to peer groups that focus on homeless youth and recovery or mentoring programs. Nurseled interventions may be responsible for connecting homeless youth with other services and supports, particularly those that foster relationship building and promote social bonding (Carlson et al., 2006; Worthington \& MacLaurin, 2013).

Family-centered approaches should become part of all homeless youth recovery interventions. The dominant care approach for homeless youth in Canada tends to overlook the integration of family (Winland, Gaetz, Stephen, \& Patton, 2011; Winland, 2013). Therefore, it is important for service providers to understand the relationships between homeless youth and specific members of their family. Interventions must assess the quality of specific family relationships and whether reconstructing specific family ties may be beneficial in the recovery of the youth. In some situations, it may not be beneficial to the client to connect with all family members however the value of familial support from specific members should not be overlooked in treatment (Winland et al., 2011; Windland, 2013). If youth have positive relationships with some family members, the family members should be educated on how to support the youth as they transition out of homelessness. In addition to this study, the literature underlines the importance of supportive familial relationships during periods of transition which is reflective of homeless youth seeking recovery (Nebbitt, House, Thompson, \& Pollio, 2007; Krabbenborg, Boersma, \&Wolf, 2013; Hughes et al., 2010). 


\section{Implications for Policy}

As found in this study, social support was correlated with perceptions of recovery. To encourage the formation of positive social and peer bonds, interventions may see benefit from approaches focused on the promotion of healthy supportive relationships. Policy aimed at implementing and funding recreational activities at local community centres (i.e. sports games, crafts, etc.) for the general youth population may remove the stigma that affect homeless youth encouraging them to attend such activities. During these activities, service providers may be present to provide access to care while creating a social environment that promotes peer relationships. Stakeholders include municipal government bodies, i.e. city of London, responsible for funding recreational activities at local community centres. Provincial organizations such as Public Health Ontario (PHO) and the Ministry of Health and Long-term Care (MHLTC) would be responsible for ensuring adequate staffing so service providers can be available during recreational activities. Larger social networks have been found to increase levels of access to mental health services and important for psychological well-being (Kidd, 2003; Kurtz, Lindsey, Jarvis, \& Nackerud, 2000). Creating a safe space for homeless youth to go where they have the opportunity to discuss their issues, questions, or challenges may facilitate the development of supportive relationships between youth with common goals and service providers.

Some homeless youth are unable to reconstruct relationships with family members however these youth still require supportive relationships as they transition through recovery (Winland, 2013). In situations where family relationships are unable to be reconstructed, mentor services could be integrated into care plans to provide support. Mentor support policies should be created to both guide the mentors involved in the program and supervise the relationship to 
ensure it is conducive to achieving health. Mentors can consist of volunteers, service providers, etc. The policy should promote continuity, longevity, and successful outcomes for each homeless youth. The policy must reinforce the importance of all mentors to openly listen, assess, and consult with service providers regarding issues that surpass their expertise to maximize health and recovery.

Many of the participants in this study had no contact with service providers demonstrating that this population has limited access to supports. Policies aimed at strengthening outreach efforts through street-based outreach initiatives must be implemented to educate homeless youth of services available and encourage their participation. For youth living in areas with little or no access to services, enrollment assistance in service clinics must be implemented. Assisting in the enrollment of services may include transportation for these youth to come to various clinics or for services and providers to provide support in remote areas. Stakeholders in this process include local public health units, service agencies, and shelters for homeless youth. PHO is another important stakeholder, central to implementing a mandate that focuses on service outreach initiatives and evaluation of methods. Fostering consistency of outreach initiatives and evaluation of methods will ensure that homeless youth in every city across Ontario have improved access to services.

\section{Implications for Service Provider Education}

All service providers must understand the importance and impact of social supports and family relationships throughout the recovery process of homeless youth. PHO's Priority Populations Project (2015), enacted to promote the health of vulnerable populations, has identified homeless adolescents and young adults as priority populations (Tyler \& Hassen, 2015). This mandate proposes the need for educational programs to help practitioners support priority 
populations. Findings from this study can supplement the educational programs by highlighting the importance and maintenance of supportive relationships. Service providers must be aware of how to assess the quality of relationships between peers and family to ensure the youth have supportive relationships. The service provider can play an important role in strengthening positive supportive environments or removing the youth from relationships with negative influences and little support. Providers must foster consistency in the relationships between homeless youth, their friends, and their family. Education can take the form of face-to-face workshops, online learning modules, shadow shifts, etc. Service providers have the ability to take an active role in the care of homeless youth and therefore must understand their role in providing prevention, safety, and stabilization of services.

\section{Recommendations for Future Research}

There are a number of areas that future research can address to overcome some of the limitations of this study as well as expand on or test Peplau's Theory of Interpersonal Relations (1952, 1991). First, it is important to understand the quality of the relationship between service providers and homeless youth's health and recovery outcomes. Service providers are often the first points of access into the system for these youth and assist them in navigating through and accessing the supports and interventions they need. A supportive relationship with service providers have been deemed a necessary building block on the road to recovery (Angell \& Mahoney, 2007; Deegan, 2001; Farkas \& Anthony, 2010; Moran, Zisman-Ilani, Garber-Epstein, \& Roe, 2014; Slade, 2009). Therefore, such studies may examine the impact of therapeutic relationships or positive working alliances between service providers and homeless youth. Studies may examine the impact of the relationship on a number of health outcomes in addition to perceptions of recovery including, substance use reduction, mental health symptom 
management, adherence to treatment plans, improved QoL, and improved sense of selfconfidence and esteem. Obtaining the perspective of both the service provider and the homeless youth is necessary in designing and implementing multifaceted, client-centered intervention strategies.

Understanding the impact of various social supports that the homeless youth interacts with may be helpful in securing and enhancing supportive relationships. Studies may examine which social supports the homeless youth perceives as most supportive in their health and recovery, whether that is peers, older adults, service providers, etc. Understanding that relationships with family members are positively correlated to perceptions of recovery among homeless youth (Hughes et al., 2010; Kurtz et al., 2000), research may examine different approaches and interventions to reconnect specific family members. Methods to reconnect family would differ depending on the family history and present dynamics. Examining different approaches that incorporate some family members into the recovery process may be beneficial to the health of the youth.

\section{Summary and Conclusion}

The results of this study contribute further research evidence that support the applicability of Peplau's $(1952,1991,1992)$ Theory of Interpersonal Relations in the health and recovery of homeless youth. In this study, network of service providers was not significantly associated with homeless youth's perceptions of recovery. However, both social support and family relations were significantly and positively associated with perceptions of recovery. These results reinforce the importance of supportive interpersonal relationships, whether they are between peers or family, in the recovery process of homeless youth. In dealing with a client population that is so vulnerable, unsupported, and at risk of multiple challenges that extend beyond the mere physical 
self, it is critical that nurses and other service providers ensure that all client's receive holistic, client-centered care. The diversity of each homeless youth requires the assessment and evaluation of unique health needs throughout the recovery process. Although recovery from homelessness is a complex process, findings from this study suggest the importance of a network of supportive relationships in helping youth recover from homelessness. 


\section{References}

Angell, B., \& Mahoney, C. (2007). Re-conceptualizing the case management relationship in intensive treatment: a study of staff perceptions and experiences. Administration and Policy in Mental Health and Mental Health Services Research, 34, 172-188.

Aviles, A., \& Helfrich, C. (2004). Life skill service needs: Perspectives of homeless youth. Journal of Youth and Adolescence, 33(4), 331-338.

Bartle-Haring, S. (2012). The utility of mentoring homeless adolescents: A pilot study. The American Journal of Drug and Alcohol Abuse, 38(4), 350-358.

Carlson, J. L., Sugano, E., Millstein, S. G., \& Auerswald, C. L. (2006). Service utilization and the life cycle of youth homelessness. Journal of Adolescent Health, 38(5), 624-627.

Cheng, T., Wood, E., Nguyen, P., Kerr, T., \& DeBeck, K. (2014). Increases and decreases in drug use attributed to housing status among street-involved youth in a Canadian setting. Harm Reduction Journal, 11(1), 1-6.

Christiani, A., Hudson, H., Nyamathi, A., Mutere, M., \& Sweat, J. (2008). Attitudes of homeless and drug-using youth regarding barriers and facilitators in delivery of quality and culturally sensitive health care. Journal of Child \& Adolescent Psychiatric Nursing, 21, $154-163$.

Dawson, A., \& Jackson, D. (2013). The primary health care service experiences and needs of homeless youth: A narrative synthesis of current evidence. Contemporary Nurse: A Journal for the Australian Nursing Profession, 44(1), 62-75.

Day, C., Islam, M., White, A., Reid, S. E., Hayes, S., \& Haber, P. (2011). Development of a nurse-led primary healthcare service for injecting drug users in inner-city Sydney. Australian Journal of Primary Health, 17(1), 10-15.

Deegan, P.E. (2001). Recovery as a self-directed process of healing and transformation. In C. Brown (Ed.). Recovery and Wellness: Models of Hope and Empowerment for People with Mental Illness. New York: Haworth Press.

Farkas, M., Anthony, W.A. (2010). Psychiatric rehabilitation interventions: A review. International Review of Psychiatry, 22, 114-129.

Feng, C., DeBeck, K., Kerr, T., Mathias, S., Montaner, J., \& Wood, E. (2013). Homelessness independently predicts injection drug use initiation among street-involved youth in a Canadian setting. The Journal of Adolescent Health, 52(4), 499-501.

Forchuk, C. (1991). Peplau's theory: Concepts and their relations. Nursing Science Quarterly, $4(2), 54-60$. 
Garrett, S., Higa, D., Phares, M., Peterson, P., Wells, E., \& Baer, J. (2008). Homeless youths' perceptions of services and transitions to stable housing. Evaluation and Program Planning, 31(4), 436-444.

Gavin, L. E., Catalano, R. F., David-Ferdon, C., Gloppen, K. M., \& Markham, C. M. (2010). A review of positive youth development programs that promote adolescent sexual and reproductive health. Journal of Adolescent Health, 46(3), 75-91.

Heinze, H. J., Jozefowicz Hernandez, D. M., \& Toro, P. A. (2010). Taking the youth perspective: Assessment of program characteristics that promote positive development in homeless and at-risk youth. Children and Youth Services Review, 32(10), 1365-1372.

Hughes, J. R., Clark, S. E., Wood, W., Cakmak, S., Cox, A., Macinnis, M., . . Broom, B. (2010). Youth homelessness: The relationships among mental health, hope, and service satisfaction. Journal of the Canadian Academy of Child and Adolescent Psychiatry, 19(4), 274-283.

Kidd, S. A. (2003). Street youth: Coping and interventions. Child and Adolescent Social Work Journal, 20(4), 235-261.

Krabbenborg, M. A. M., Boersma, S. N., \& Wolf, J. R. L. M. (2013). A strengths based method for homeless youth: Effectiveness and fidelity of Houvast. BMC Public Health, 13(1), 359-359.

Kurtz, P. D., Lindsey, E. W., Jarvis, S., \& Nackerud, L. (2000). How runaway and homeless youth navigate troubled waters: The role of formal and informal helpers. Child and Adolescent Social Work Journal, 17(5), 381-402.

Lindsey, E. W., Kurtz, P. D., Jarvis, S., Williams, N. R., \& Nackerud, L. (2000). How runaway and homeless youth navigate troubled waters: Personal strengths and resources. Child and Adolescent Social Work Journal, 17(2), 115-140.

McCay, E., Quesnel, S., Langley, J., Beanlands, H., Cooper, L., Blidner, R., . . Bach, K. (2011). A relationship-based intervention to improve social connectedness in street-involved youth: A pilot study. Journal of Child and Adolescent Psychiatric Nursing, 24(4), 208215.

Moran, G.S., Zisman-Ilani, Y., Garber-Epstein, P., \& Roe, D. (2014). Adaptation and psychometric assessment of the Hebrew version of the recovery promoting relationships scale (RPRS). Psychiatric Rehabilitation Journal, 37, 31-36

Nebbitt, V. E., House, L. E., Thompson, S. J., \& Pollio, D. E. (2007). Successful transitions of runaway/homeless youth from shelter care. Journal of Child and Family Studies, 16(4), 545-555. 
Nyamathi, A., Liu, Y., Marfi see, M., Shoptaw, S., Gregerson, P., Saab, S., ... Gelberg, L. (2009). Effects of a nurse-managed program on hepatitis A and B vaccine completion among homeless adults. Nursing Research, 58(1), 13-22.

Nyamathi, A., Hudson, A., Greengold, B., Slagle, A., Marfisee, M., Khalilifard, F., \& Leake, B. (2010). Correlates of substance use severity among homeless youth. Journal of Child and Adolescent Psychiatric Nursing, 23(4), 214-222.

Peplau, H. E., (1952). Interpersonal relations in nursing: A conceptual frame of reference for psychodynamic nursing. New York: G. P. Putnam's Sons

Peplau, H. E. (1991). Interpersonal relations in nursing: A conceptual frame of reference for psychodynamic nursing. New York: Springer Publishing Company.

Peplau, H.E. (1992). Interpersonal relations: A theoretical framework for application in nursing practice. Nursing Science Quarterly, 5(1), 13-18.

Peplau, H.E. (1997). Peplau's theory of interpersonal relations. Nursing Science Quarterly, 10(4), 162-167.

Rachlis, B.S., Wood, E., Zhang, R., Montaner, J. S., Kerr, T. (2009). High rates of homelessness among a cohort of street-involved youth. Health Place, 15, 10-17

Slade, M. (2009). Personal recovery and mental illness: A guide for mental health professionals. Cambridge, NY: Cambridge University Press.

Tyler, I., \& Hassen, N. (2015). Priority populations project: Understanding and identifying priority populations for public health in Ontario. Ontario Agency for Health Protection and Promotion (Public Health Ontario), Toronto, ON: Queen's Printer for Ontario

Werner, E. E., \& Smith, R. S. (1992). Overcoming the odds: High risk children from birth to adulthood. Ithaca: Cornell University Press.

Williams, N., Jarvis, S., Kurtz, P. D., \& Lindsey, E. (2001). From trauma to resiliency: Lessons from former runaway and homeless youth. Journal of Youth Studies, 4(2), 233-253.

Winland, D., Gaetz, Stephen., \& Patton, T. (2011). Family matters: Homeless youth and Eva's initiatives "family reconnect" program. Toronto: The Canadian Homelessness Research Network Press.

Winland, D. (2013). Reconnecting with Family and Community: Pathways Out of Youth Homelessness. In S. Gaetz, B. O’Grady, K. Buccieri, J. Karabanow, \& A. Marsolais (Eds.), Youth Homelessness in Canada: Implications for Policy and Practice (pp. 15-38). Toronto: Canadian Homelessness Research Network Press.

Worthington, C., \& MacLaurin, B. (2013). Promoting health for homeless and street-involved youth: Use and views of services of street-involved youth in Calgary. In S. Gaetz, B. 
O'Grady, K. Buccieri, J. Karabanow, \& A. Marsolais (Eds.). Youth homelessness in Canada: Implications for policy and practice (pp. 161-183). Toronto, Ontario: Canadian Homelessness Research Network 


\section{VITA}

Name:

Post-secondary Education and Degrees

Honours and Awards

Related Work Experience

Professional Memberships
Sara A. Gasior

University of Western Ontario

London, Ontario, Canada

Bachelor of Science in Nursing (BScN)

2009-2013

University of Western Ontario

London, Ontario, Canada

Masters of Science in Nursing (MScN)

2013-2015

Dean's Honor List

2009-2010, 2010-2011, 2011-2012, 2012-2013, 2013-2014, 2014-2015

Honor Society of Nursing

Iota Omicron Chapter of Sigma Theta Tau International (STTI)

2013-2015

Registered Nurse (RN)

Acute Medicine Unit

University Hospital

London, Ontario

2013-2015

Advanced Practice Nurse- Clinical Nurse Specialist (CNS) Acute Pain Service

Humber River Hospital

Toronto, Ontario

2015-Current

Registered Nurses' Association of Ontario (RNAO)

College of Nurses of Ontario (CNO)

Canadian Nurses Association (CNA) 